\title{
Turbulent Forced Convection and Heat Transfer Characteristic in a Circular Tube with Modified-Twisted Tapes
}

\author{
Amnart Boonloi ${ }^{1}$ and Withada Jedsadaratanachai ${ }^{2}$ \\ ${ }^{1}$ Department of Mechanical Engineering Technology, College of Industrial Technology, \\ King Mongkut's University of Technology North Bangkok, Bangkok 10800, Thailand \\ ${ }^{2}$ Department of Mechanical Engineering, Faculty of Engineering, King Mongkut's Institute of Technology Ladkrabang, \\ Bangkok 10520, Thailand \\ Correspondence should be addressed to Withada Jedsadaratanachai; kjwithad@kmitl.ac.th
}

Received 16 October 2015; Revised 9 December 2015; Accepted 10 December 2015

Academic Editor: Shripad T. Revankar

Copyright ( $) 2016$ A. Boonloi and W. Jedsadaratanachai. This is an open access article distributed under the Creative Commons Attribution License, which permits unrestricted use, distribution, and reproduction in any medium, provided the original work is properly cited.

\begin{abstract}
Heat transfer, pressure loss, and thermal performance assessment in a circular tube heat exchanger with modified-twisted tapes are reported. The rectangular holes are punched out from the general twisted tape to reduce the pressure loss. The influences of the hole sizes $(l / D, \mathrm{LR}=0.30,0.44,0.78$, and 0.88$)$ and twisted ratios $(y / D, \mathrm{TR}=1,1.5,2$, and 4$)$ for the single and double twisted tapes are investigated with a numerical method at turbulent regime, $\mathrm{Re}=3000-10,000$. The finite volume method and the SIMPLE algorithm are used to investigate for the current research. The numerical results are reported in terms of flow structure and heat transfer behavior and compared with the smooth tube and the regular twisted tape. It is found that the modified-twisted tape provides higher heat transfer rate than the smooth tube due to the longitudinal vortex flows, created by the twisted tape. The longitudinal vortex flows help to increase fluid mixing. The rectangular punched holes of the twisted tape can reduce the pressure loss of the heating system. In addition, the maximum thermal enhancement factor is around 1.39 and 1.31 for the double twisted tape and single twisted tape, respectively, at $\mathrm{Re}=3000, \mathrm{LR}=0.78$, and $\mathrm{TR}=1$.
\end{abstract}

\section{Introduction}

Twisted tape is a type of vortex generators, inserted in heat exchangers to improve heat transfer rate and thermal efficiency. The twisted tape can generate swirling flows or longitudinal vortex flows through the tube heat exchanger. Moreover, the strong swirling flow may impinge on the tube surface that helps to reduce the thickness of the thermal boundary layer. Due to easy forming and installing of the twisted tape in the tube heat exchanger, the twisted tape has been used in many engineering works: chemical process, condenser, shell-and-tube heat exchanger, heat recovery, solar air heater, and so forth. The twisted tape not only increases in the heat transfer rate but also increases in the pressure loss. Many parameters of the twisted tape, twisted ratio, twisted length, twisted width, and configuration, are important factors that should be investigated. The experimental and numerical investigations on the thermal characteristic in the heat exchanger with the twisted tape have been widely reported.

For example, Piriyarungrod et al. [1] investigated heat transfer augmentation in a tube heat exchanger with tapered twisted tapes at $\operatorname{Re}=6000-20,000$. The influences of the twisted ratios, $y / W=3.5,4.0$, and 4.5 , and the taper angles, $0^{\circ}, 0.3^{\circ}, 0.6^{\circ}$, and $0.9^{\circ}$, were reported. They found that the heat transfer rate tends to increase with decrease in taper angle and twisted ratio. They also concluded that the maximum thermal enhancement factor is around 1.05 at $\operatorname{Re}=6000$ and $y / W=$ 3.5. Promvonge [2] experimental studied heat transfer, pressure loss, and thermal performance in a square channel with combined $30^{\circ} \mathrm{V}$-fins and quadruple counter-twisted tapes (called "V-finned counter-twisted tape") at turbulent regime, $\operatorname{Re}=4000-30,000$. Promvonge [2] reported that the V-finned counter-twisted tape gives a higher thermal performance than the quadruple twisted tape only. Promvonge [2] also claimed that the maximum thermal enhancement factor is 
around 1.75 at $\operatorname{Re}=4000$. Hindasageri et al. [3] studied the heat transfer distributions of swirling flame jet impinging on a flat plate with using twisted tape for $\mathrm{Re}=500-2500$. They presented that the enhancement of heat flux is around $40-140 \%$ at low Reynolds number. Eiamsa-ard et al. [4] investigated the heat transfer improvement of $\mathrm{TiO}_{2} /$ water in a tube heat exchanger with overlapped dual twisted tapes by a numerical method. They summarized that the use of the overlapped dual twisted tapes in the tube heat exchanger gives higher heat transfer rate around $28.1 \%$ when compared with general twisted tape. Rios-Iribe et al. [5] illustrated the heat transfer analysis of a non-Newtonian fluid in a circular tube with twisted tapes for laminar regime, $\mathrm{Re}=0.2-600$. They found that the twisted tapes produce the swirling flows through the test section, which help to improve the heat transfer rate. Chokphoemphun et al. [6] experimentally investigated heat transfer, pressure loss, and efficiency in a tube heat exchanger with multiple twisted tapes at $\operatorname{Re}=5300-24,000$. They stated that the heat transfer and friction loss in the tube heat exchanger inserted with the multiple twisted tapes are around 1.15-2.12 times and 1.9-4.1 times over the smooth tube, respectively. They also said that the quadruple counter-twisted tape has the highest thermal performance. Khoshvaght-Aliabadi and Eskandari [7] studied the heat transfer, friction loss, and thermal performance of $\mathrm{Cu}$-water nanofluid in a tube heat exchanger with twisted tapes by an experimental method at $\operatorname{Re}=7500-15,000$ (turbulent regime). They presented that the nonuniform twisted length provides higher heat transfer rate and pressure loss than the twisted tape with uniform twisted length. They also reported that the $0.3 \mathrm{wt} \%$ concentration of nanofluid for the twisted tape with low to high twisted length performs the overall enhancement ratio around $87 \%$. Salman et al. [8] numerical investigated heat transfer and friction loss in a circular tube heat exchanger with quadrant-cut twisted tape (QCT) using a numerical method. The effects of twisted ratios and cut depths for the QCT were presented. They indicated that the QCT with the twisted ratio of 2.93 and the cut depth of $0.5 \mathrm{~cm}$ performs the highest heat transfer rate and friction loss. Maddah et al. [9] experimentally studied heat transfer and pressure loss in a horizontal double pipe with modifiedtwisted tape by using $\mathrm{Al}_{2} \mathrm{O}_{3}$ /water as working fluid. They concluded that the heat transfer and friction loss tend to increase around $12-52 \%$ and $5-28 \%$, respectively. Salman et al. [10] presented heat transfer augmentation in a circular tube with elliptic-cut twisted tape (ECT) for laminar flow, Re = 200-2100. They claimed that the ECT in the tube heat exchanger provides higher heat transfer rate and thermal performance than the general twisted tape. Kanizawa et al. [11] analyzed experimentally the heat transfer and pressure loss of R134a in a tube heat exchanger with twisted tape. The twisted tape with twisted ratios of $3,4,9$, and 14 was investigated. They found that the reduction of the twisted tape leads to higher thermal enhancement factor. Pal and Saha [12] presented the use of centre-cleared twisted tape to enhance heat transfer rate in a corrugated tube heat exchanger at laminar flow. They found that the centre-cleared twisted tape can enhance both the heat transfer and thermal performance in the corrugated tube heat exchanger when comparing with the base case. Naik et al. [13] compared between twisted tape and wire coil on thermal performance in a tube heat exchanger at turbulent regime, $\mathrm{Re}=4000-20,000$. They reported that the augmentation on the heat transfer rate is around $17.62 \%, 31.88 \%$, and $44.45 \%$ for plain tube, inserted with twisted tape and inserted with wire coil, respectively, of $0.3 \%$ concentration nanofluid at $\mathrm{Re}=20,000$ compared to water. They also presented that the friction loss is around 1.149, 1.179, and 1.198 times above the base case for plain tube, inserted with twisted tape and inserted with wire coil, respectively. The thermal enhancement factor is around 1.24 and 1.36 for the twisted tape and wire coil, respectively, which is concluded by Naik et al. [13]. Eiamsa-ard et al. [14] studied heat transfer augmentation in a tube heat exchanger with regular-spaced twisted tape by both numerical and experimental methods. The influences of twisted ratios, 6 and 8, and spaced ratios, 1,2, and 3, were reported. They found that the heat transfer rate increases with decreasing twisted ratio and spaced ratios. They also concluded that the regular-spaced twisted tape can reduce the pressure when compared with the general twisted tape with no spaced ratio. Azmi et al. [15] reported heat transfer rate and pressure loss of $\mathrm{TiO}_{2}$ nanofluid in a tube with twisted tape at $\mathrm{Re}=8000-30,000$. They claimed that the heat transfer rate and friction loss are around $81.1 \%$ and 1.5 times above the base case (water is used as working fluid), respectively, at $\mathrm{Re}=23,558$ with $1 \%$ concentration of nanofluid. Salman et al. [16] selected parabolic-cut twisted tape (PCT) was inserted in a circular tube heat exchanger to enhance the heat transfer rate and thermal efficiency of nanofluid flow. They pointed out that the PCT with the twisted ratio of 2.93 and cut depth of $0.5 \mathrm{~cm}$ gives the higher Nusselt number around $10 \%$ when compared with the classical twisted tape. Salman et al. [17] reported that heat transfer in a tube heat exchanger with V-cut twisted tape is increased around 107\%. Ghadirijafarbeigloo et al. [18] numerically studied turbulent flow and heat transfer characteristic in a receiver tube of solar parabolic trough concentrator with louvered twisted tape at turbulent regime. The effects of twisted ratios, 2.67, 4, and 5.33 , were depicted. They presented that the heat transfer coefficient and friction loss tend to increase significantly when compared with typical plain twisted tape in the tube and smooth tube with no twisted tape. Azmi et al. [19] selected twisted tape to enhance the heat transfer rate and performance in a tube heat exchanger by using $\mathrm{SiO}_{2} /$ water and $\mathrm{TiO}_{2}$ /water as working fluids. The affectations of twisted ratios, 5-93, for the Reynolds numbers of 5000-25,000 were investigated experimentally. They summarized that the heat transfer enhancement is around $27.9 \%$ and $11.4 \%$ for $\mathrm{SiO}_{2}$ and $\mathrm{TiO}_{2}$, respectively, at $0.3 \%$ concentration and the twisted ratio of 5. Waghole et al. [20] experimentally investigated heat transfer and thermal efficiency in absorber/receiver of parabolic trough collector with twisted tape. The silver nanofluid was selected as working fluid in the parabolic trough collectors. The effects of twisted ratios, 0.577-1.732, were studied on the heat transfer rate and pressure loss for the Reynolds numbers, $\operatorname{Re}=500-6000$. They found that the Nusselt number and friction factor are around 1.25-2.10 times and 1.0-1.75 times over the base case (plain absorber/receiver of parabolic trough collector), respectively, while the thermal 
performance is around 1.35-2.05. Durga Prasad et al. [21] presented the experimental results of heat transfer and friction loss in a U-tube heat exchanger inserted with helical tape. The $\mathrm{Al}_{2} \mathrm{O}_{3}$ nanofluid was used as tested fluid in the tube heat exchanger. The helical pitch ratios, 5, 10, 15, and 20 , were studied for the Reynolds number, $R e=3000-30,000$, with the nanofluid concentrations of $0.01 \%$ and $0.03 \%$. They stated that the helical pitch ratio of 5 and $0.03 \%$ concentration gives the heat transfer rate around $32.91 \%$ as compared to water. Maddah et al. [22] studied effects of twisted tape and nanofluid in a double pipe heat exchanger on heat transfer and pressure loss. They found that the twisted tape and nanofluid perform higher heat transfer rate around 10-25\% with a moderate pressure loss penalty. Bhuiya et al. [23] illustrated the experimental results on the thermal characteristics in a tube heat exchanger with perforated twisted tapes. The influences of porosities, 1.6, 4.5, 8.9, and $14.7 \%$, were studied for the Reynolds number, $\mathrm{Re}=7200-49,800$. They indicated that the Nusselt number, friction loss, and thermal efficient when using the perforated twisted tape in the tube heat exchanger are higher that the smooth tube around 110$340 \%, 110-360 \%$, and $28-59 \%$, respectively. Nanan et al. [24] selected the helically twisted tapes to induce co- and counterswirling flows in a tube heat exchanger. The effects of pitch ratios, 1 and 2, for width ratio and twisted ratio of 0.2 and 0.3 were studied at turbulent regime, $R e=6000-20,000$. They reported that the cohelical twisted tape performs lower heat transfer rate and pressure loss but gives a higher thermal performance than the counter helical twisted tape. Eiamsaard and Wongcharee [25] investigated heat transfer characteristic in a microfin tube with double twisted tapes at $\operatorname{Re}=5650-17,000$. They pointed out that the double twisted tapes, which produce the counter swirling flows, give the best thermal performance due to stronger vortex flows. Eiamsaard et al. [26] presented the use of combined turbulators, circular ring and twisted tape, in a tube heat exchanger with the main aim of augmenting thermal performance. The pitch ratios, $1,1.5$, and 2 , of the circular ring and the twisted ratios, 3,4 , and 5 , of the twisted tape were investigated for the Reynolds number, $R e=6000-20,000$. They reported that the Nusselt number, friction factor, and thermal performance when using the combined turbulators in the tube heat exchanger are around $25.8 \%, 82.8 \%$, and $6.3 \%$, respectively, higher than the circular ring alone. They also said that the best thermal performance is around 1.42 at pitch ratio and twisted ratio of 1 and 3, respectively. Salam et al. [27] investigated the augmentations on both heat transfer rate and thermal efficiency in a tube heat exchanger with rectangular cut twisted tapes by an experimental method. They concluded that the Nusselt number and friction loss tend to increase around 2.3-2.9 times and 1.4-1.8 times, respectively, over the smooth tube when using the rectangular cut twisted tapes in the tube heat exchanger. They also indicated that the thermal performance in the test tube is around 1.9-2.3. Naik et al. [28] experimentally studied heat transfer and pressure loss for water-propylene glycol $(70: 30 \%$ by volume) based $\mathrm{CuO}$ nanofluid in a tube with twisted tapes. The effects of nanofluid concentrations, $0.025 \%, 0.1 \%$, and $0.5 \%$, and twisted ratios,
$5-15$, were investigated for the Reynolds number, $1000<\operatorname{Re}$ $<10,000$. They found the enhancements of heat transfer rate are around $27.95 \%$ for the $0.5 \% \mathrm{CuO}$ in the smooth tube and around $76.06 \%$ over the base fluid at the twisted ratio of 5 .

As the above literature reviews, the heat exchanger inserted with the twisted tape can improve the heat transfer rate and thermal efficiency due to the generation of the swirling flow through the tube. The proposed twisted tapes can be readily manufactured by forming process and conveniently installed in the actual heat exchanger system. However, the twisted tape not only increases in heat transfer rate but also gives a large pressure loss, especially at low twisted ratio. In the current work, the perforation method is selected to reduce the pressure loss in the heating system. The twisted tapes are punched with rectangular holes at various sizes and inserted in a circular tube heat exchanger. The numerical investigation is selected in the present work to describe flow structure and heat transfer characteristic when inserting the twisted tap in the tube. The understanding of the flow and heat transfer mechanisms may help to improve the new design of heat exchanger and also save costs of the energy.

\section{Circular Tube Geometry and Computational Domain}

The twisted tape with width ratio, $W / D=0.98$, is inserted in a circular tube heat exchanger as depicted in Figure 1. The diameter of the test tube is equal to $0.05 \mathrm{~m}$ for all cases. The influences of twisted ratios $(y / W$ or TR $=1,1.5,2$, and 4$)$ and length ratios $(l / W$ or $L R=0.3,0.44,0.78$, and 0.88$)$ of the single modified-twisted tape are investigated for the Reynolds number, $R e=3000-10,000$. The rectangular holes are set with constant gap ratio $(g / W)$ and hole length ratio $(e / W)$ of 0.03 and 0.07 , respectively. The double twisted tapes in the tube heat exchanger, shown in Figure 2, are studied for $L R=0.78$ and 0.88 at $\mathrm{TR}=1$.

\section{Mathematical Method, Boundary Condition, and Assumption}

The incompressible turbulent flow with steady operation in three dimensions and heat transfer characteristic in the tube are governed by the continuity equation, the Navier-Stokes equation, and the energy equation. These equations with ignoring natural convection, viscous dissipation, body forces, and radiation heat transfer can be written in the Cartesian tensor system as follows.

Continuity equation is as follows:

$$
\frac{\partial}{\partial x_{i}}\left(\rho u_{i}\right)=0 .
$$

Momentum equation is as follows:

$$
\frac{\partial}{\partial x_{i}}\left(\rho u_{i} u_{j}\right)=-\frac{\partial P}{\partial x_{i}}+\frac{\partial}{\partial x_{j}}\left[\mu\left(\frac{\partial u_{i}}{\partial x_{j}}-\rho \overline{u_{i}^{\prime} u_{j}^{\prime}}\right)\right],
$$




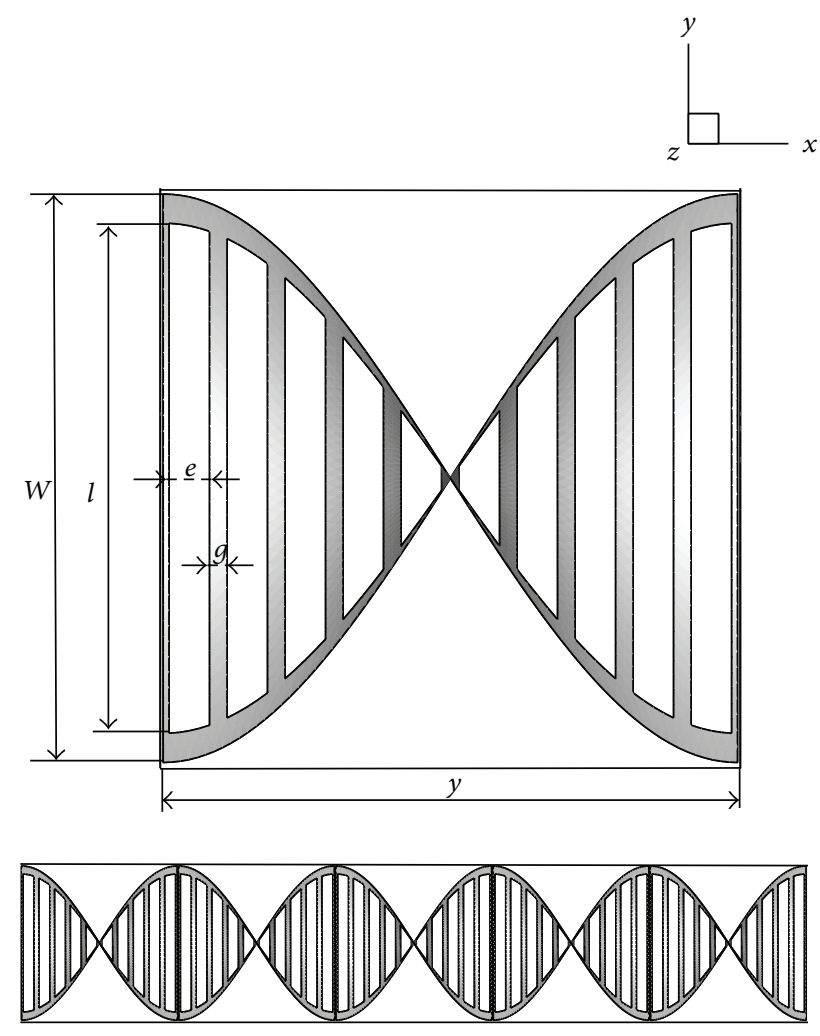

FIGURE 1: Modified-twisted tape inserted in the tube heat exchanger.

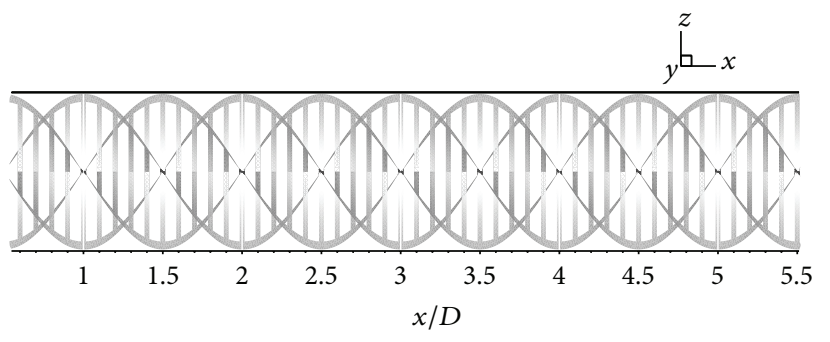

(a)

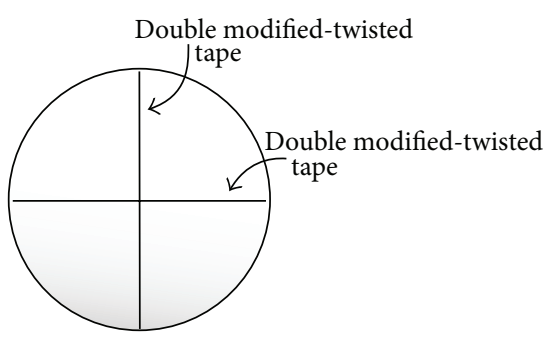

(b)

FIGURE 2: Double twisted tape inserted in the tube heat exchanger in (a) $x z$ plane and (b) diagram in $y z$ plane.

where

$$
-\rho \overline{u_{i}^{\prime} u_{j}^{\prime}}=\mu_{t}\left(\frac{\partial u_{i}}{\partial x_{j}}+\frac{\partial u_{i}}{\partial x_{i}}\right)-\frac{2}{3}\left(\rho k+\mu_{t} \frac{\partial u_{i}}{\partial x_{i}}\right) \delta_{i j}
$$

where $\rho, P, \mu$ are the density, pressure, and dynamic viscosity of fluid, respectively, and $u^{\prime}, u_{i}$ are a fluctuating component of velocity and a mean component of velocity in the direction $x_{i}$, respectively. For the turbulent flow in three-dimensional problems, the turbulent kinetic energy, $k$, can be written as $k=(1 / 2) \overline{u_{i}^{\prime} u_{j}^{\prime}}$ and $\delta_{i j}$ is a Kronecker delta. An advantage of the Boussinesq approach with the computation of the relatively low computational cost associated with the computation of the turbulent viscosity, $\mu_{t}$, given is $\mu_{t}=\rho c_{\mu} k^{2} / \varepsilon$.
Energy equation is as follows:

$$
\frac{\partial}{\partial x_{i}}\left(\rho u_{i} T\right)=\frac{\partial}{\partial x_{j}}\left(\left(\Gamma+\Gamma_{t}\right) \frac{\partial T}{\partial x_{j}}\right),
$$

where $\Gamma$ and $\Gamma_{t}$ are molecular thermal diffusivity and turbulent thermal diffusivity, respectively. The diffusivities can be expressed as

$$
\begin{gathered}
\Gamma=\frac{\mu}{\operatorname{Pr}} \\
\Gamma_{t}=\frac{\mu_{t}}{\operatorname{Pr}_{t}} .
\end{gathered}
$$


For the present numerical solutions, the realizable $k-\varepsilon$ turbulent model is used which is presented by Launder and Spalding [29]. Consider

$$
\begin{aligned}
& \frac{\partial}{\partial t}(\rho k)+\frac{\partial}{\partial x_{j}}\left(\rho k u_{j}\right) \\
& =\frac{\partial}{\partial x_{j}}\left[\left(\mu+\frac{\mu_{t}}{\sigma_{k}}\right) \frac{\partial k}{\partial x_{j}}\right]+G_{k}+G_{b}+\rho \varepsilon-Y_{M} \\
& \quad+S_{k}, \\
& \frac{\partial}{\partial t}(\rho \varepsilon)+\frac{\partial}{\partial x_{j}}\left(\rho \varepsilon u_{j}\right) \\
& =\frac{\partial}{\partial x_{j}}\left[\left(\mu+\frac{\mu_{t}}{\sigma_{\varepsilon}}\right) \frac{\partial \varepsilon}{\partial x_{j}}\right]+\rho C_{1} S \varepsilon-\rho C_{2} \frac{\varepsilon^{2}}{k+\sqrt{v \varepsilon}} \\
& +C_{1 \varepsilon} \frac{\varepsilon}{k} C_{3 \varepsilon} G_{b}+S_{\varepsilon},
\end{aligned}
$$

where

$$
C_{1}=\max \left[0.43, \frac{\eta}{\eta+5}\right], \quad \eta=S \frac{k}{\varepsilon}, S=\sqrt{2 S_{i j} S_{i j}} ;
$$

the constants in the model are given as follows:

$$
\begin{aligned}
C_{1 \varepsilon} & =1.44, \\
C_{2} & =1.9, \\
\sigma_{k} & =1.0, \\
\sigma_{\varepsilon} & =1.2,
\end{aligned}
$$

where $S_{k}$ and $S_{\varepsilon}$ are user-defined source terms and $\sigma_{k}$ and $\sigma_{\varepsilon}$ are the turbulent Prandtl numbers for $k$ and $\varepsilon$, respectively.

For the convection terms, the SIMPLE algorithm for handling the pressure-velocity coupling and the SOU scheme are solved using a finite volume approach [30]. The energy equation is considered to be converged when the normalized residual values are less than $10^{-9}$ while the other variables are less than $10^{-5}$.

In the present study, to analysis the flow behavior and heat transfer characteristic, the Reynolds number, friction factor, Nusselt number, and thermal enhancement factor are the most important parameters, which can be written as follows.

The Reynolds number is as follows:

$$
\operatorname{Re}=\frac{\rho u_{0} D}{\mu} .
$$

The friction factor is defined as

$$
f=\frac{(\Delta P / L) D}{2 \rho \bar{u}^{2}},
$$

where $\Delta P$ is the pressure drop, $D$ is the tube diameter, and $u$ is mean flow velocity.

The local Nusselt number is given by

$$
\mathrm{Nu}_{x}=\frac{h_{x} D}{k}
$$

where $h$ is the convective heat transfer coefficient and $k$ is the thermal conductivity.

The average Nusselt number can be obtained by

$$
\mathrm{Nu}=\frac{1}{A} \int \mathrm{Nu}_{x} d A
$$

Thermal performance enhancement factor (TEF) is defined as the ratio of the heat transfer coefficient of an augmented surface, $h$, to that of a smooth surface, $h_{0}$, under the constant pumping power condition. TEF can be calculated from

$$
\mathrm{TEF}=\left.\frac{h}{h_{0}}\right|_{\mathrm{pp}}=\left.\frac{\mathrm{Nu}}{\mathrm{Nu}_{0}}\right|_{\mathrm{pp}}=\frac{\left(\mathrm{Nu} / \mathrm{Nu}_{0}\right)}{\left(f / f_{0}\right)^{1 / 3}},
$$

where $f_{0}$ and $\mathrm{Nu}_{0}$ are the friction factor and the Nusselt number of the smooth tube, respectively.

The inlet and outlet of the tube are obtained to be periodic boundaries. At the wall, a no-slip condition is defined and obtained to be a constant heat flux. Air is chosen as the working fluid with the uniform mass flow rate at $300 \mathrm{~K}(\mathrm{Pr}=$ 0.707 ) and its thermodynamic properties are assumed to be constant based on mean bulk temperature. The radiation heat transfer, viscous dissipation, and body force are ignored.

\section{Numerical Result}

The numerical results for the circular tube with twisted tape and double twisted tapes are divided into four parts: verification of the computational domain, influence of twisted ratio, influence of length ratio, and influence of double twisted tapes. The results are illustrated in terms of flow configuration, heat transfer behavior, and performance analysis.

4.1. Verification of the Computational Domain. The validations of the presented computational domain are done to assure that the numerical model gives high accuracy and precision results. This section can be divided into three sections: verification with the smooth tube, comparison with the experimental result, and grid independence.

The validations of the smooth tube are done by comparison between the present values with the values of the correlation [31]. Figures 3(a) and 3(b) present the verifications of the smooth circular tube for heat transfer and pressure loss in terms of Nusselt number and friction factor, respectively. As in the figures, the present results are found in excellent agreement with the values from the correlations on both Nusselt number and friction factor. The deviations for the Nusselt number and friction factor are around $\pm 11 \%$ and $\pm 10 \%$, respectively.

The comparisons between the numerical results with the experimental results [32] for the Nusselt number and friction factor of the regular single twisted tape $(\mathrm{TR}=2$, no punched, $W / D=0.98$ ) are depicted in Figures 4(a) and 4(b), respectively. The present predictions are found to agree well within $\pm 6 \%$ and $\pm 10 \%$, for the Nusselt number and friction factor, respectively.

The number of grids in the computational domain has effect on the numerical results. The optimum point between 


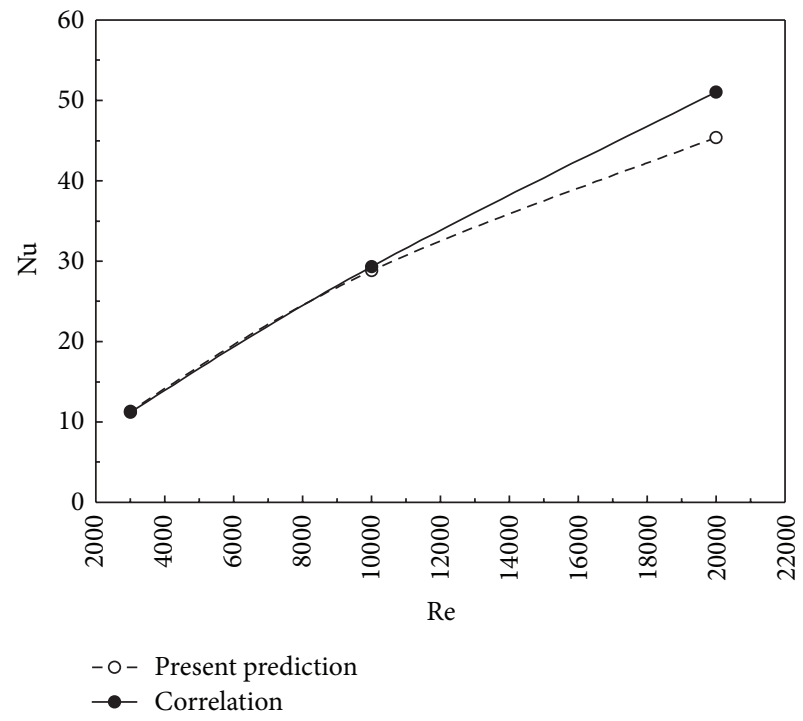

(a)

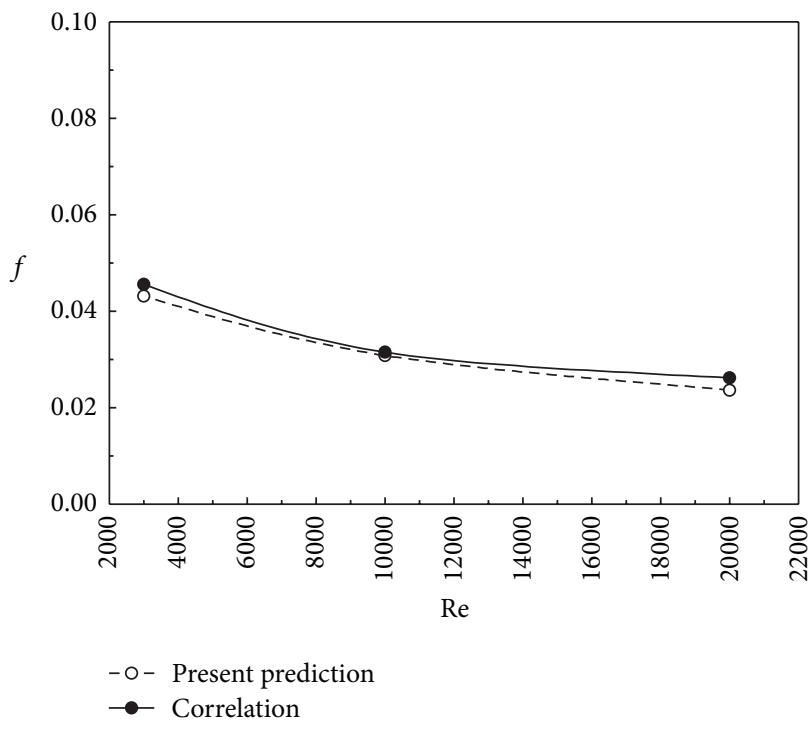

(b)

Figure 3: Verification of the smooth tube for (a) Nusselt number and (b) friction factor.

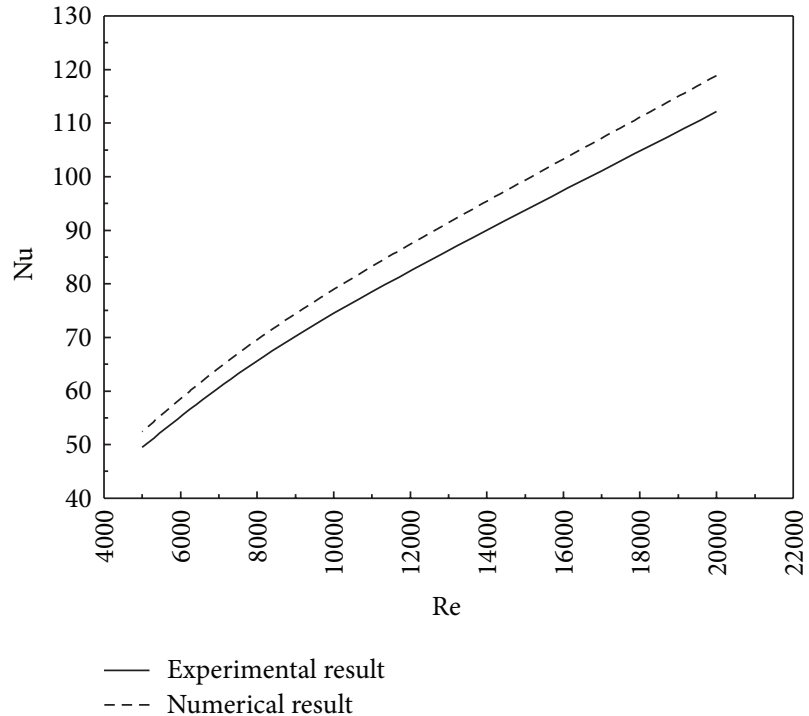

(a)

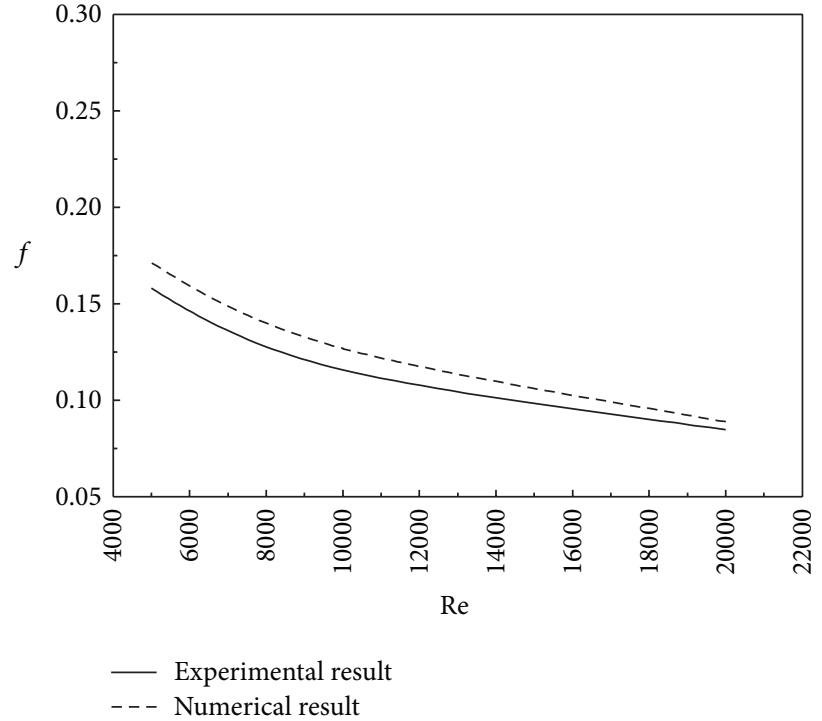

(b)

FIGURE 4: Comparison between numerical and experimental results for (a) Nusselt number and (b) friction factor of typical twisted tape at $\mathrm{TR}=1$.

the number of cells and the accuracy results is done by comparing six sets of grid cells. The number of cells, 70000, 98000, $123000,240000,303000$, and 543000, is generated for the current computational domain. The increase of grid from 240000 to 303000 has slight effect on heat transfer and friction loss. Therefore, the 240000 cells are selected for the present investigation. The grid independent test is presented in Table 1.

As all parts of the validations, it can be concluded that the present computational domain is reliable to predict heat transfer characteristic and pressure loss in the tube heat exchanger inserted with twisted tape.
4.2. Influence of Twisted Ratio. In this section, the flow configurations, heat transfer behaviors, and performance evaluations in the tube with modified-twisted tape at various twisted ratios are reported. Figures 5(a), 5(b), 5(c), and 5(d) present the tangential velocity vectors in transverse planes for the circular tube heat exchanger with the modified-twisted tape for $\mathrm{TR}=1,1.5,2$, and 4, respectively, at $\mathrm{Re}=10,000$ and $\mathrm{LR}$ $=0.88$. As in the figures, the modified-twisted tape can generate longitudinal vortex flows with clockwise rotation through the test section for all cases. The cores of the vortex flows are found at the center of the tube for all planes. The vortex flows 


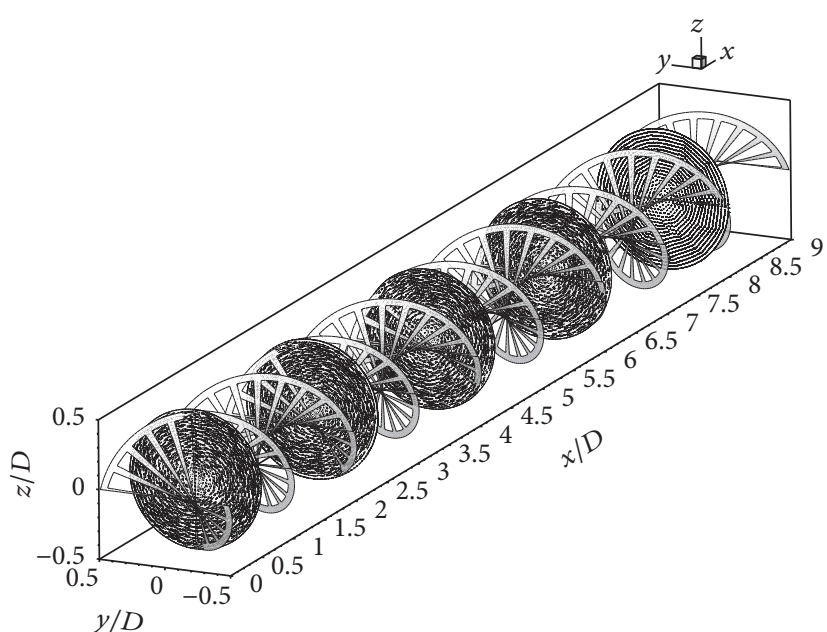

(a)

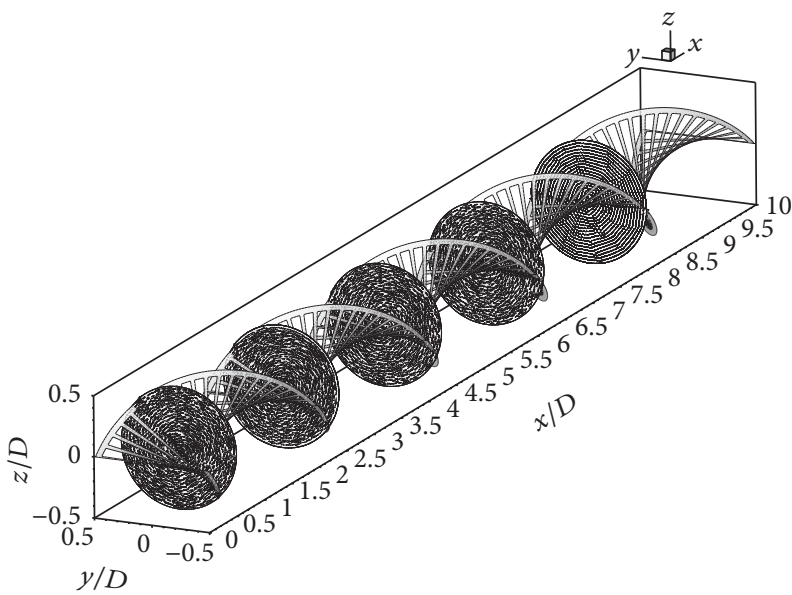

(c)

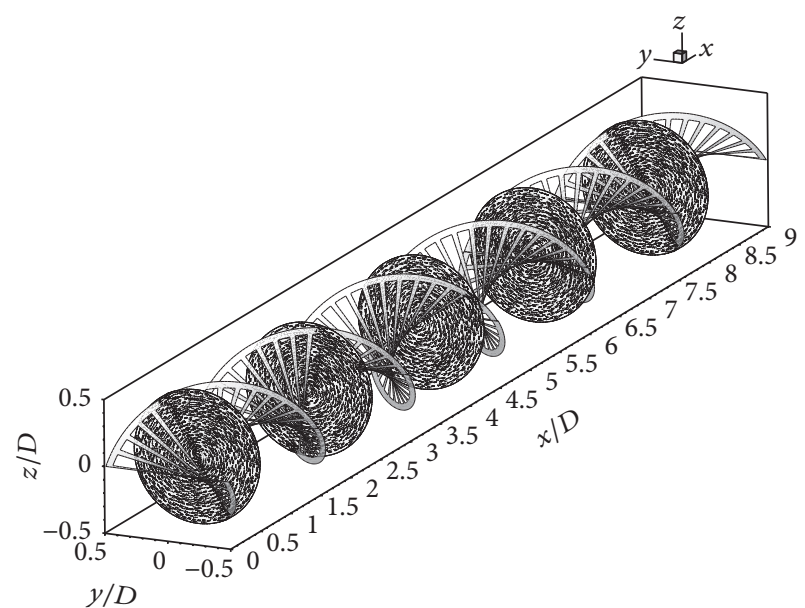

(b)

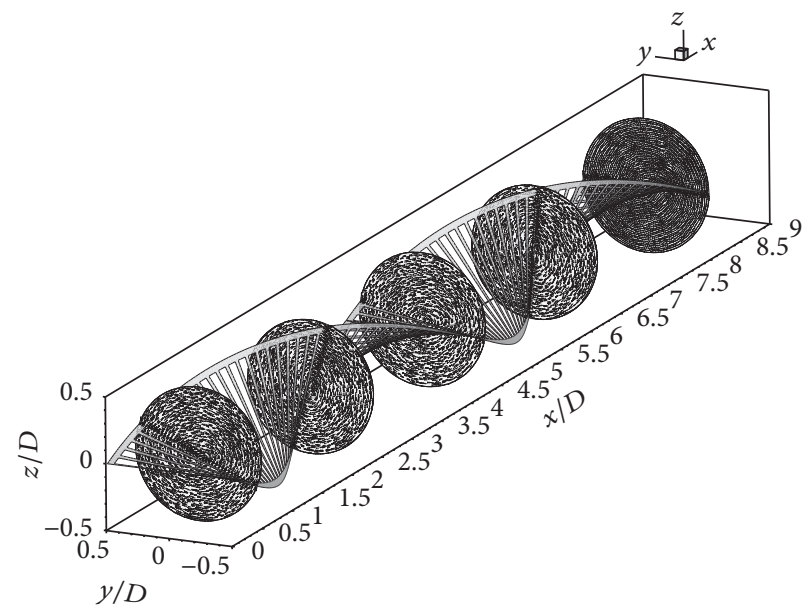

(d)

Figure 5: Tangential velocity vectors in transverse planes for (a) $\mathrm{TR}=1$, (b) $\mathrm{TR}=1.5$, (c) $\mathrm{TR}=2$, and (d) $\mathrm{TR}=4$ of the modified-twisted tape in the tube at $\mathrm{Re}=10,000$ and $\mathrm{LR}=0.88$.

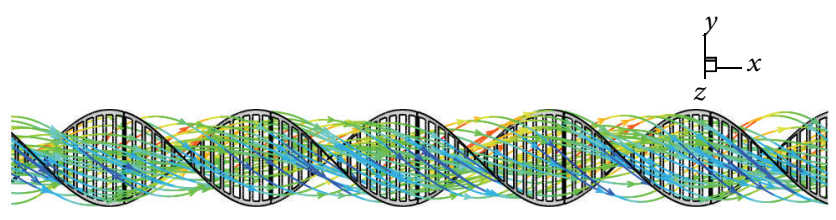

FIGURE 6: Longitudinal swirling flow in the tube with the modified-twisted tape.

help to enhance heat transfer rate due to better fluid mixing between the core of the vortex and near the tube wall regime. The longitudinal vortex flows through the test section with the modified-twisted tape are presented in Figure 6. All TR values perform a similar pattern of the flow, but the vortex strength is found to be different.

The heat transfer behaviors in the tube with modifiedtwisted tape are reported in terms of temperature distributions in transverse planes and local Nusselt number distributions on the tube wall. Figures 7(a), 7(b), 7(c), and 7(d) report the temperature distributions in transverse planes for the tube heat exchanger with the modified-twisted tape at $\mathrm{TR}=1,1.5,2$, and 4 for $\mathrm{Re}=10,000$ and $\mathrm{LR}=0.88$, respectively.
TABLE 1: Grid independent test.

\begin{tabular}{lcccc}
\hline Number of cells & $\mathrm{Nu}$ & $f$ & Nu error (\%) & $f$ error (\%) \\
\hline 543,000 & 56.52 & 2.229 & 0 & 0 \\
303,000 & 57.08 & 2.186 & -0.9908 & 1.929116 \\
240,000 & 56.78 & 2.176 & 0.525578 & 0.457457 \\
123000 & 59.33 & 2.010 & -4.49102 & 7.628676 \\
98,000 & 56.35 & 2.138 & 5.022754 & -6.36816 \\
70,000 & 49.70 & 2.098 & 11.80124 & 1.870907 \\
\hline
\end{tabular}

There are findings that the use of the modified-twisted tape leads to better mixing of the fluid flow through the test section 


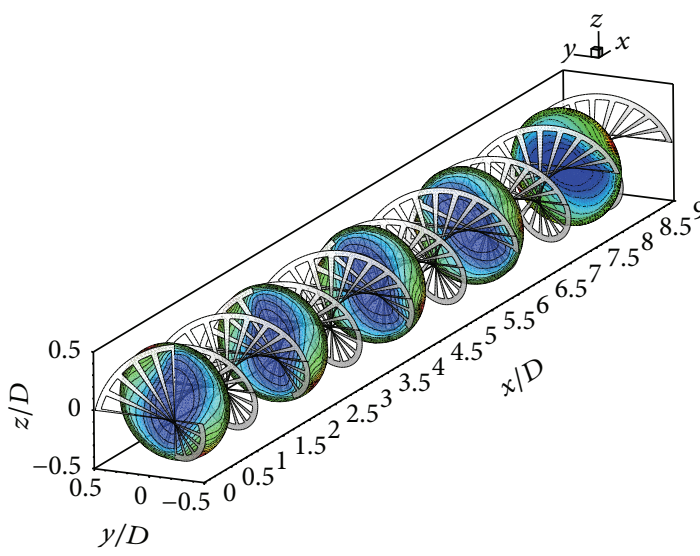

(a)

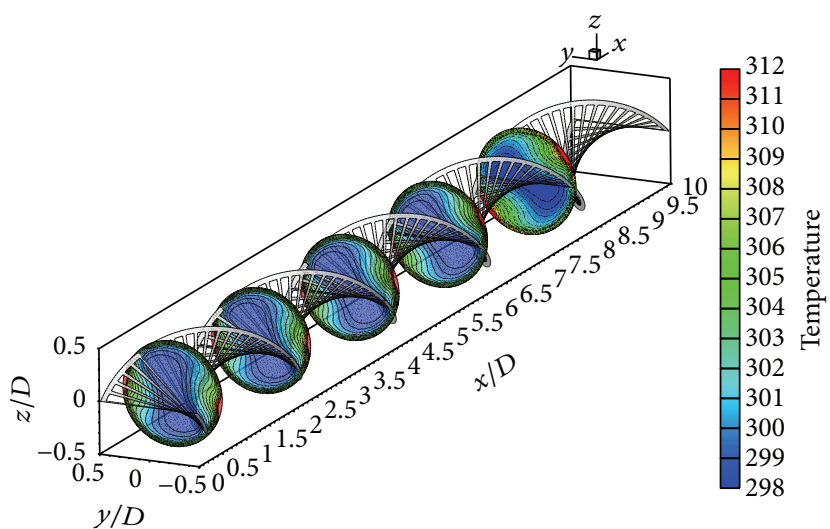

(c)

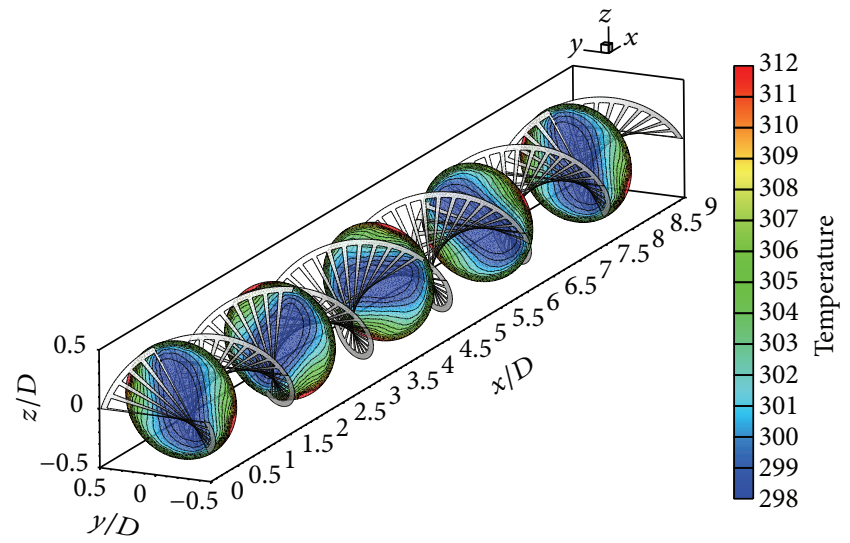

(b)

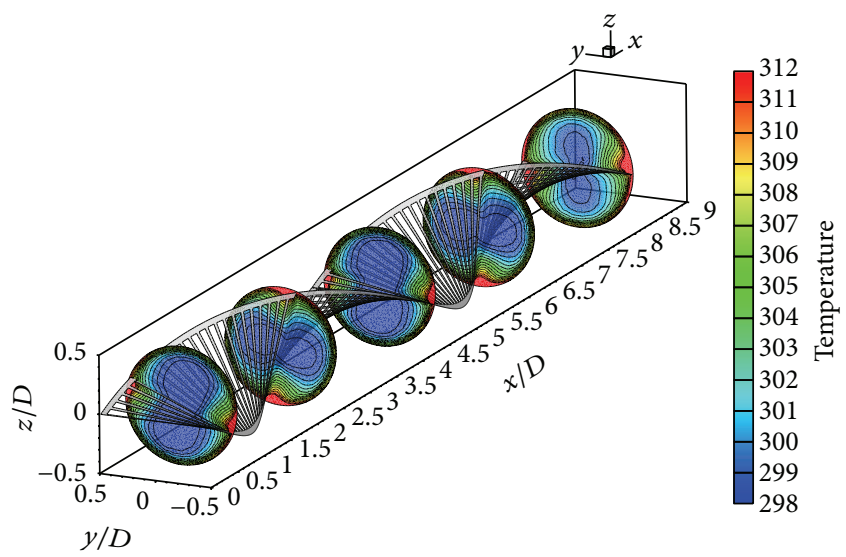

(d)

Figure 7: Temperature contours in transverse planes for (a) $\mathrm{TR}=1$, (b) $\mathrm{TR}=1.5$, (c) $\mathrm{TR}=2$, and (d) $\mathrm{TR}=4$ of the modified-twisted tape in the tube at $\mathrm{Re}=10,000$ and $\mathrm{LR}=0.88$.

in comparison with the smooth tube. Due to the vortex flows, which are created by the twisted tape, the red layer (hot fluid) of the contour is found to be thinner. The $\mathrm{TR}=1$ provides the best fluid mixing, while the $\mathrm{PR}=4$ performs the reversed results. The reason of this may be that the modified-twisted tape with the TR = 1 gives the strongest and longest vortex flows.

The local Nusselt number distributions on the tube wall with the modified-twisted tape for $\mathrm{TR}=1,1.5,2$, and 4 with $\mathrm{Re}=10,000$ and $\mathrm{LR}=0.88$ are displayed in Figures $8(\mathrm{a}), 8(\mathrm{~b})$, $8(\mathrm{c})$, and $8(\mathrm{~d})$, respectively. The red contour means high heat transfer rate, while the blue contour is in reverse meaning. The peak of heat transfer regime is found at the edge of the modified-twisted tape for the $\mathrm{TR}=1,1.5$, and 2 . The $\mathrm{TR}=1$ provides the highest heat transfer rate, while the $\mathrm{PR}=4$ gives the opposite result. The $\mathrm{TR}=1.5$ and 2 give a approximate pattern of the heat transfer behavior.

The performance evaluations in the tube with the modified-twisted tape are reported in three parts, Nusselt number ratio, friction factor ratio, and thermal enhancement factor. Figure 9 presents the relations of the Nusselt number ratio with the Reynolds number at various TR values. In general, the $\mathrm{Nu} / \mathrm{Nu}_{0}$ decreases with the rise of the Reynolds number for all cases. The use of the modified-twisted tape produces a higher heat transfer rate than the smooth tube for all TRs. The TR $=1$ gives the highest heat transfer rate, while the $\mathrm{TR}=1.5$ performs higher heat transfer rate than the $\mathrm{TR}=$ 2. The $\mathrm{TR}=4$ provides the lowest values of heat transfer rate due to the lowest vortex strength. The $\mathrm{TR}=1$ performs higher heat transfer rate than the $\mathrm{TR}=1.5,2$, and 4 around $21 \%$, $24.4 \%$, and $37 \%$, respectively, when considered at $\mathrm{Re}=3000$. The $\mathrm{Nu} / \mathrm{Nu}_{0}$ is around $2.10-2.70,1.61-2.14,1.58-2.04$, and 1.50-1.70 for the tube with the modified-twisted tape of TR = $1,1.5,2$, and 4, respectively, at $\mathrm{Re}=3000-20,000$ and $\mathrm{LR}=$ 0.88 .

Figure 10 displays the relations of the friction factor ratio with the Reynolds number at various TRs for the tube heat exchanger with the modified-twisted tape. Generally, the friction factor ratio tends to slightly decrease with increasing Reynolds number for all cases. The presence of the modifiedtwisted tape in the test tube leads to a higher pressure loss than the smooth circular tube. The modified-twisted tape with $\mathrm{TR}=1$ performs the highest friction loss, while the $\mathrm{TR}=$ 4 gives the reverse result. The large twisted ratio can help to reduce the pressure loss in the test tube. The $\mathrm{TR}=1$ gives higher pressure loss than the TR $=1.5,2$, and 4 around $40.9 \%$, 


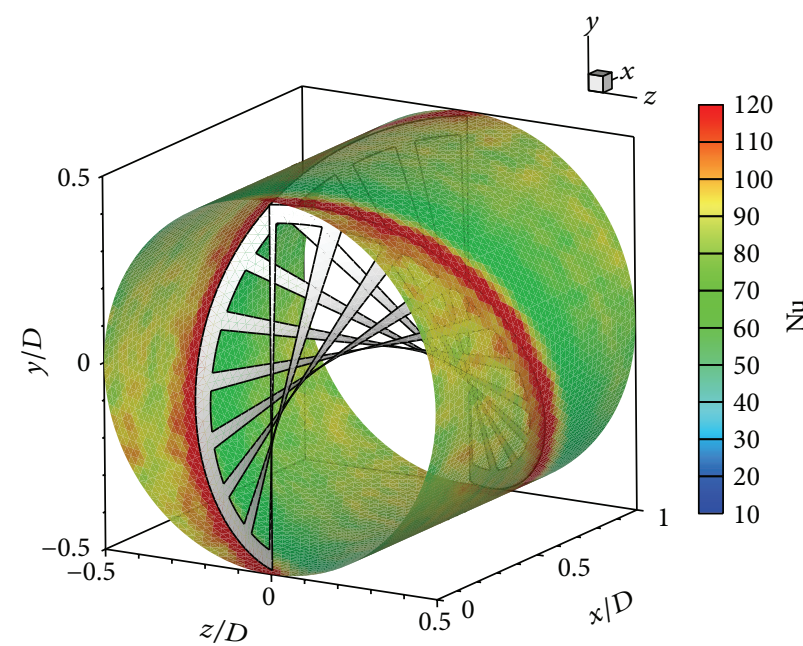

(a)

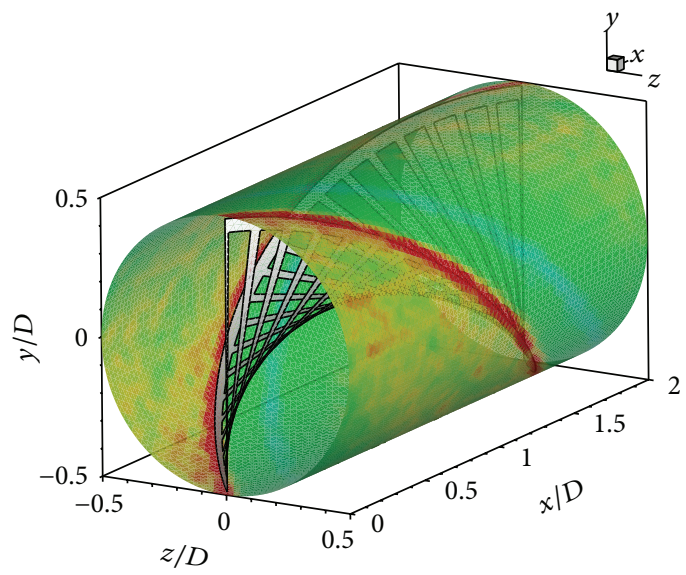

(c)

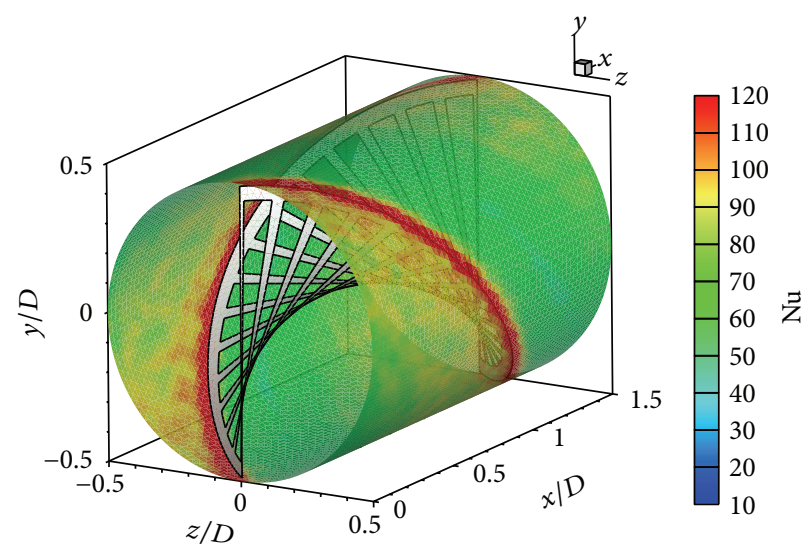

(b)

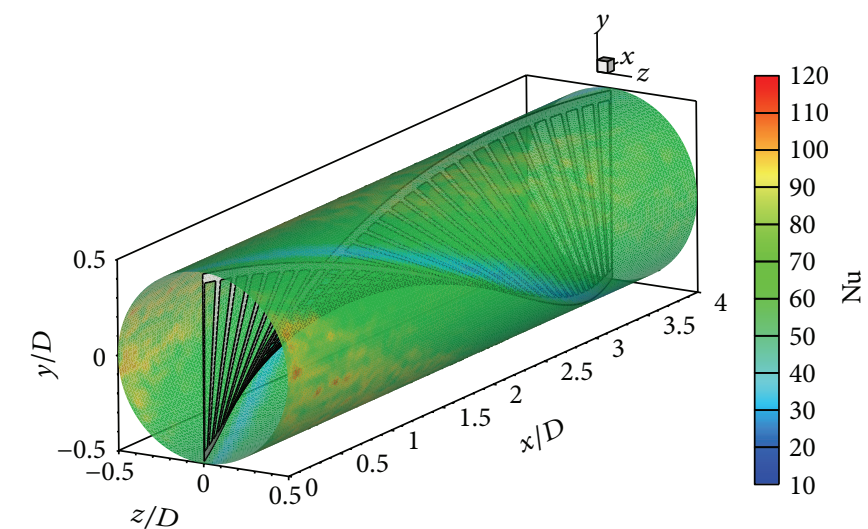

(d)

FIGURE 8: Local Nusselt number contours on the tube wall for (a) TR $=1$, (b) $\mathrm{TR}=1.5$, (c) $\mathrm{TR}=2$, and (d) $\mathrm{TR}=4$ of the modified-twisted tape in the tube at $\mathrm{Re}=10,000$ and $\mathrm{LR}=0.88$.

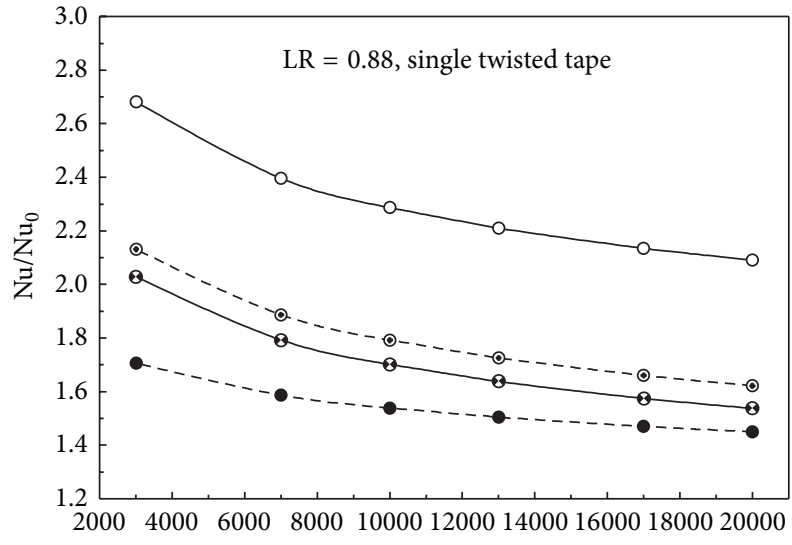

Re

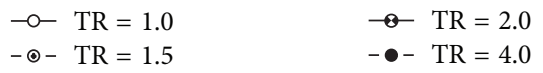

FIgURE 9: $\mathrm{Nu} / \mathrm{Nu}_{0}$ versus $\mathrm{Re}$ at various TRs.

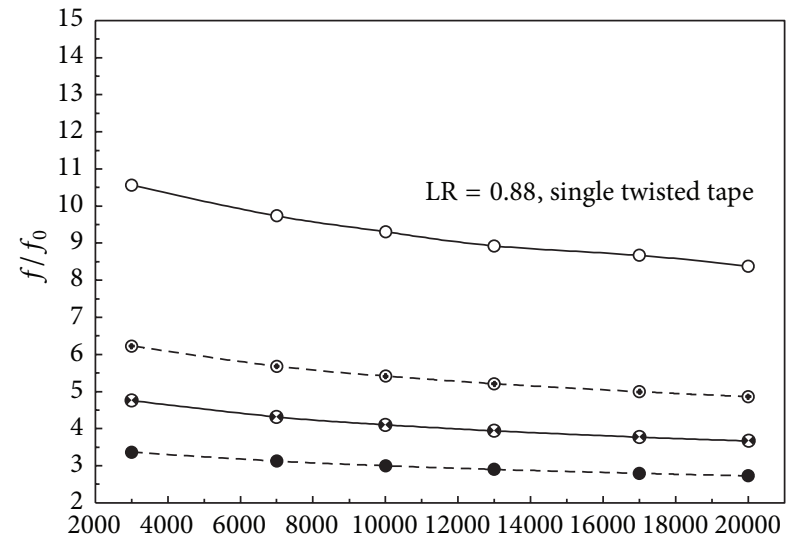

$\operatorname{Re}$

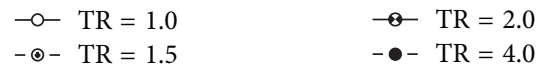

FIgURE 10: $f / f_{0}$ versus Re at various TRs. 


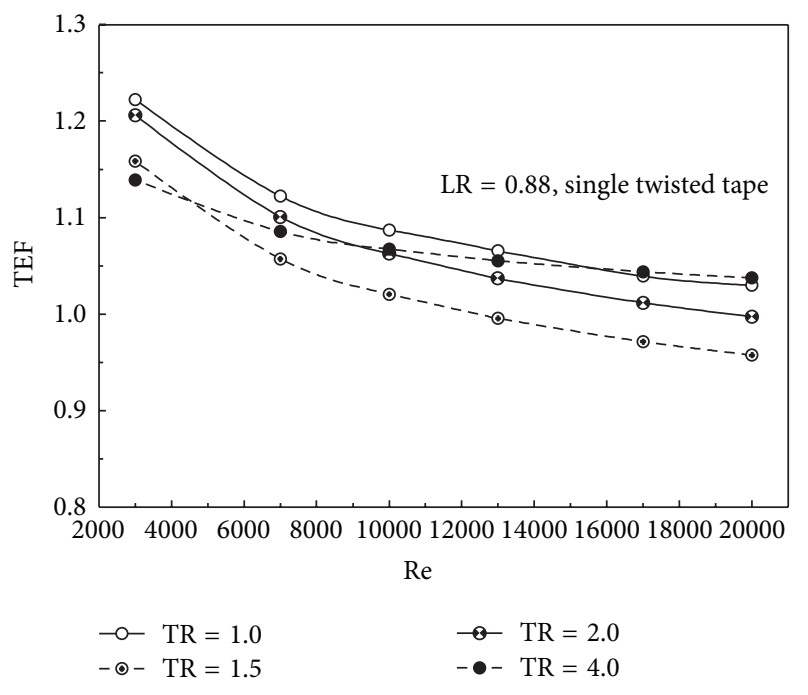

FIgURE 11: TEF versus Re at various TRs.

$57.3 \%$, and $69.1 \%$, respectively, when considered at $\mathrm{Re}=3000$. The maximum $f / f_{0}$ of the tube with the modified-twisted tape is around 11, 6.5, 4.7, and 3.4, respectively, for $\mathrm{TR}=1$, $1.5,2$, and 4 .

The variations of the thermal enhancement factor with the Reynolds number at various TRs are depicted in Figure 11. Almost all cases give higher thermal enhancement factor than the smooth tube (TEF $>1$ ). The TEF tends to decrease when the Reynolds number for all TRs increases. The highest TEF of the tube heat exchanger with the modified-twisted tape is found at $\mathrm{TR}=1, \mathrm{Re}=3000$ around 1.22. In range investigations, the modified-twisted tape in the tube gives the TEF around $0.96-1.23$ depending on the $\mathrm{Re}$ and TR values.

4.3. Influence of Length Ratio. The effects of the rectangular punched holes on the modified-twisted tape in the tube heat exchanger in terms of length ratio $(l / W, L R)$ are investigated. The $\mathrm{LR}=0.30,0.44,0.78$, and 0.88 of the modified-twisted tape are selected to investigate the single twisted ratio of 1 . The flow configurations for the modified-twisted tape at various LRs are reported in terms of longitudinal vortex flow through the test section. The difference of the length ratio has no effect on flow structure. The modified-twisted tape with $\mathrm{LR}=0.44$ can generate the flow profile as LR $=0.88$ (see Figure 12).

The temperature distributions in transverse planes at various $x / D$ and $L R$ values for the tube heat exchanger with the modified-twisted tape are presented in Figure 13. All cases give a better fluid mixing between the core and the tube wall regime. This is because of the longitudinal vortex flow, which generated from the modified-twisted tape.

The heat transfer behaviors in terms of the local Nusselt number distributions on the circular tube wall with the modified-twisted tape are shown in Figures 14(a), 14(b), 14(c), and $14(\mathrm{~d})$, respectively, for $\mathrm{LR}=0.30,0.44,0.78$, and 0.88 at $\mathrm{Re}=10,000$ and $\mathrm{TR}=1$. The peak of heat transfer regime (red contour) is found at the edge of the modified-twisted tape for all cases. The local Nusselt number on the tube wall found very close pattern for all cases.
The thermal performance in the tube heat exchanger at various LRs is reported in three parts, Nusselt number ratio, friction factor ratio, and thermal enhancement factor. The variations of the $\mathrm{Nu} / \mathrm{Nu}_{0}$ with the Reynolds number at various LRs are displayed in Figure 15. The Nusselt number ratio decreases when Reynolds number for all LR values increases. The $\mathrm{LR}=0.30,0.44$, and 0.78 perform approximate values of heat transfer rate for all the Reynolds number. The $\mathrm{LR}=0.88$ gives lower heat transfer rate than the $L R=0.30,0.44$, and 0.78 at $3000 \leq \operatorname{Re} \leq 10,000$ but provides higher heat transfer rate when $\operatorname{Re}>10,000$. The highest Nusselt number is found at $\mathrm{Re}=3000, \mathrm{LR}=0.78$ around 3.15 times higher than the smooth tube.

Figure 16 reports the variations of the friction factor ratio with the Reynolds number at various LRs for the tube heat exchanger with the modified-twisted tape. The $f / f_{0}$ tends to decrease with the rise of the Reynolds number for all cases. The $\mathrm{LR}=0.30$ of the modified-twisted tape performs highest friction loss, while the $L R=0.88$ gives the opposite result. It can be concluded that the large length ratio of the rectangular punched hole on the modified-twisted tape can help to reduce the pressure loss in the heating system. The maximum $f / f_{0}$ is around $15.5,15.2,12.7$, and 10.5 , respectively, for $\mathrm{LR}=0.30$, $0.44,0.78$, and 0.88 at $\operatorname{Re}=3000$.

The variations of the thermal enhancement factor with the Reynolds number at various LRs in the tube heat exchanger are depicted in Figure 17. The TEF decreases with increase in the Reynolds number for all LRs. The use of the modified-twisted tape with $\mathrm{LR}=0.88$ performs higher TEF than the smooth tube (TEF $>1)$ for all Reynolds numbers. The computational results reveal that the $\mathrm{LR}=0.30$ and 0.44 give upper TEF when $\operatorname{Re}<10,000$, while the $\mathrm{LR}=0.78$ provides higher TEF when $\operatorname{Re}<12,000$. The optimal TEF is around 1.31 at $\mathrm{LR}=0.78$ and $\mathrm{Re}=3000$.

4.4. Influence of Double Twisted Tapes. The use of the single modified-twisted tape inserted in the circular tube heat exchanger can enhance the heat transfer rate and thermal performance. The maximum thermal enhancement factor is around 1.31 at $\mathrm{LR}=0.78, \mathrm{TR}=1$, and $\mathrm{Re}=3000$. To improve thermal performance higher than the above results, the double twisted tapes are created. The rectangular punched holes with $\mathrm{LR}=0.78$ and 0.88 and single twisted ratio, $\mathrm{TR}=1$, are selected for the double twisted tape. The numerical results in this section are reported in forms of flow structure, heat transfer behavior, and thermal performance assessment.

The tangential velocity vectors in transverse planes for the tube heat exchanger with the double modified-twisted tapes are reported in Figure 18. As in the figure, the double modified-twisted tapes can generate the flow structure as the single modified-twisted tape; the longitudinal vortex flows are found through the test section. The longitudinal vortex flows help to increase fluid mixing when considering the temperature distributions in transverse planes as depicted in Figure 19. The double modified-twisted tapes give better fluid mixing than the single modified-twisted tape.

The local Nusselt number distributions, displayed in Figure 20, indicate that the peak of heat transfer regime is 


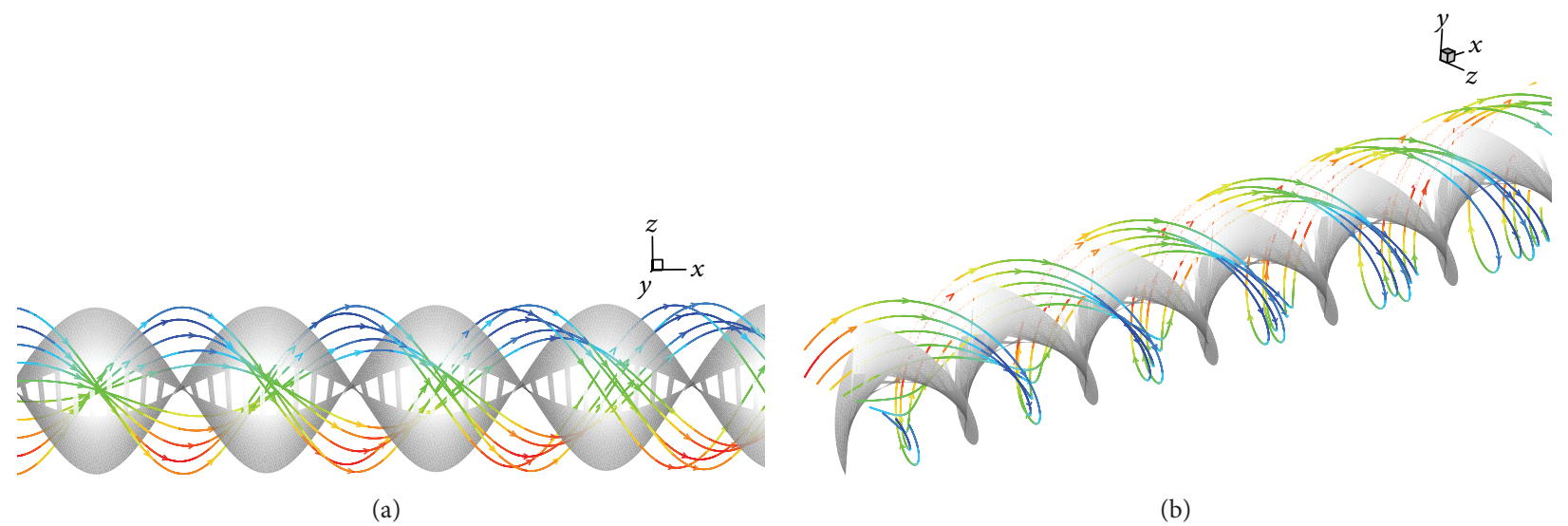

FIGURE 12: Longitudinal swirling flow in the tube with the modified-twisted tape at LR $=0.44$.

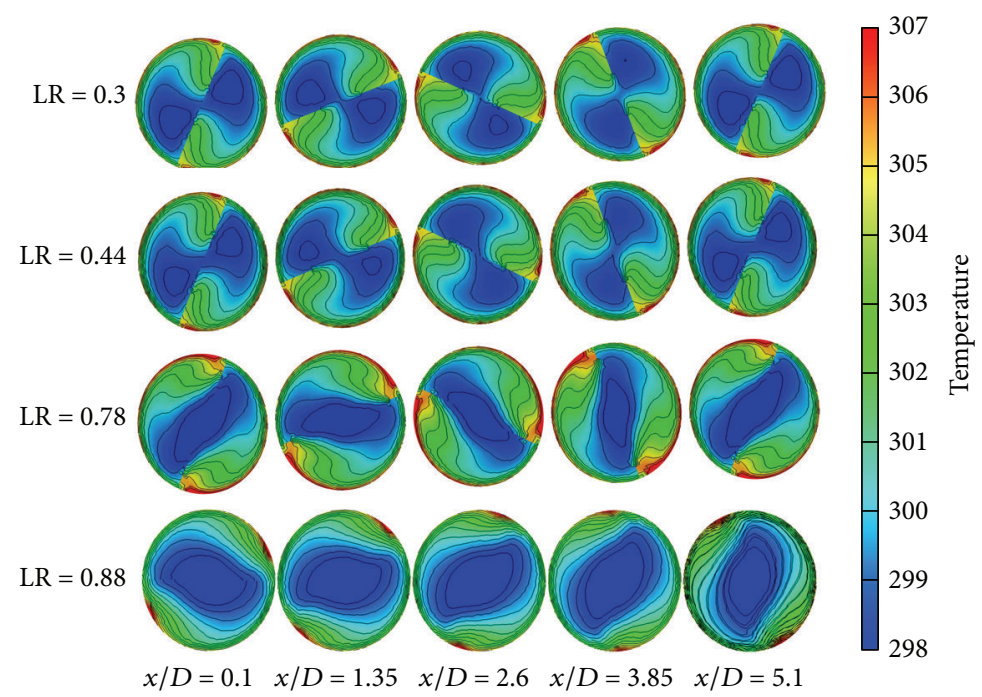

FIGURE 13: Temperature distributions in transverse planes at various LR values.

higher than the single modified-twisted tape. The highest heat transfer region is found at the edge of the double twisted tapes similar to the single twisted tape.

The performance assessments, Nusselt number ratio, friction factor ratio, and thermal enhancement factor, of the circular tube heat exchanger with the double modified-twisted tapes are presented in Figures 21-23. The variations of the Nusselt number ratio with the Reynolds number at various cases are reported in Figure 21. The $\mathrm{Nu} / \mathrm{Nu}_{0}$ tends to decrease with the rise of the Reynolds number for all cases. The double twisted tape has higher heat transfer rate than the single twisted tape for all LRs. The LR $=0.78$ of the double modifiedtwisted tape gives the highest heat transfer rate around 3.6 times over the smooth circular tube with no twisted tape. For the double twisted tapes, the LR $=0.78$ gives higher Nusselt number ratio than the $\mathrm{LR}=0.88$ around $8.33 \%$. At a similar length ratio, $L R=0.78$, the double twisted tapes perform greater Nusselt number ratio than the single twisted tape around $15.3 \%$.
The variations of the friction factor ratio with the Reynolds number with various cases for the tube heat exchanger of the single and double twisted tapes are illustrated in Figure 22. The $f / f_{0}$ declines with the rise of the Reynolds number for all cases. The double twisted tapes perform higher pressure loss than the single twisted tape on both $L R$ values. The $L R=0.78$ performs higher friction loss than the $\mathrm{LR}=0.88$ for both tapes. For double twisted tapes, the friction factor is around 12.4-18.0 and 11.0-16.5 times over the smooth tube, respectively, for $L R=0.78$ and 0.88 . In addition, the single modified-twisted tape can reduce the pressure loss in comparison with the double modified-twisted tapes.

The relations of the thermal enhancement factor with the Reynolds number with various cases are shown in Figure 23. In general, the TEF decreases with the rise of the Reynolds number. The maximum TEF is found at $\mathrm{LR}=0.78, \mathrm{Re}=3000$ of the double twisted tapes around 1.39. In range studies, the use of the double twisted tapes in the tube heat exchanger gives the TEF around 0.94-1.39. 


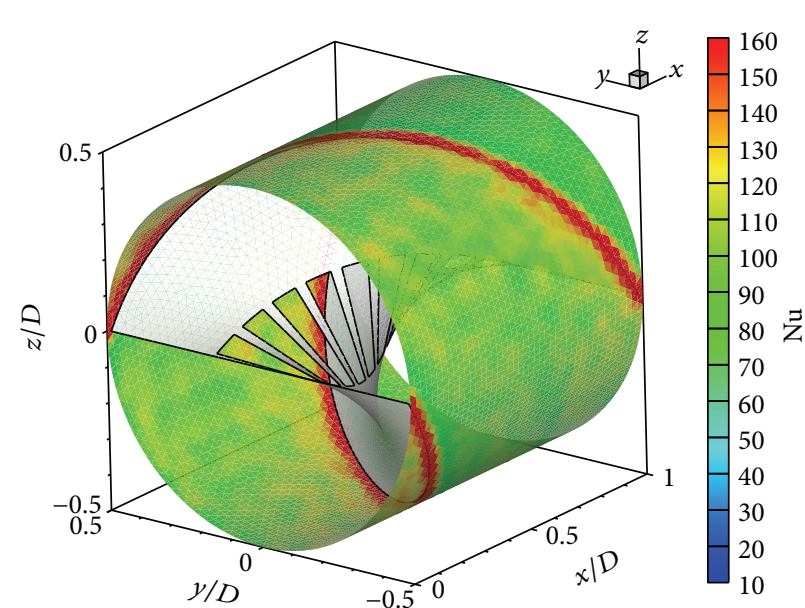

(a)

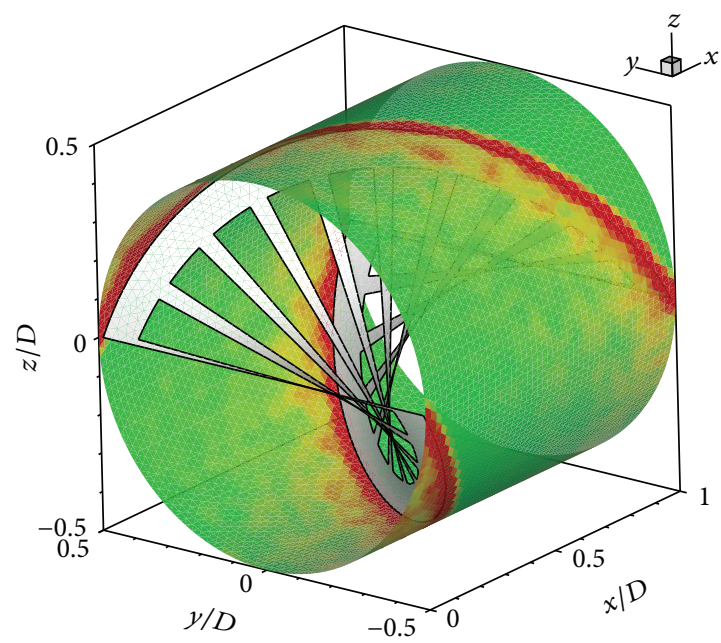

(c)

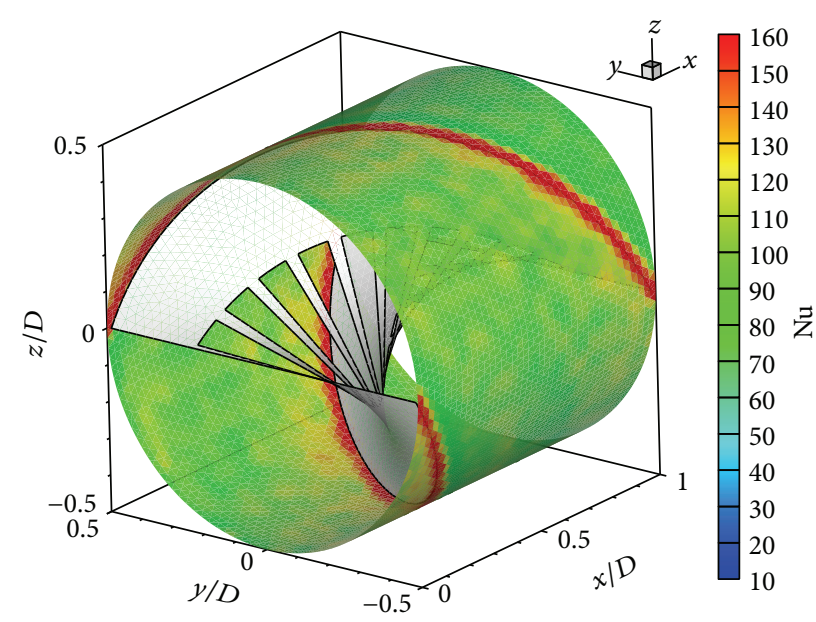

(b)

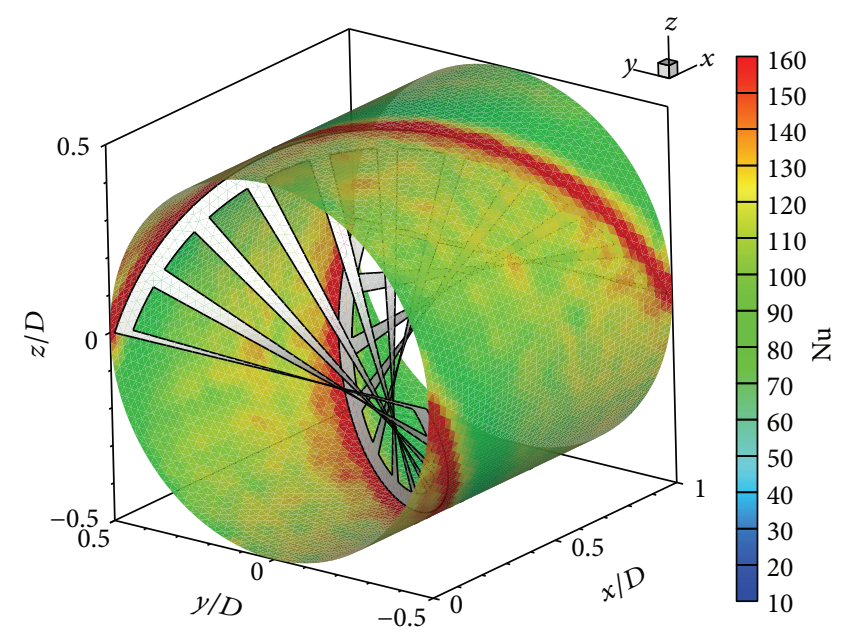

(d)

Figure 14: Local Nusselt number distributions on the tube wall of (a) LR $=0.3$, (b) $L R=0.44$, (c) $L R=0.78$, and (d) $L R=0.88$ for the tube with the modified-twisted tape at $\mathrm{TR}=1$ and $\mathrm{Re}=10,000$.

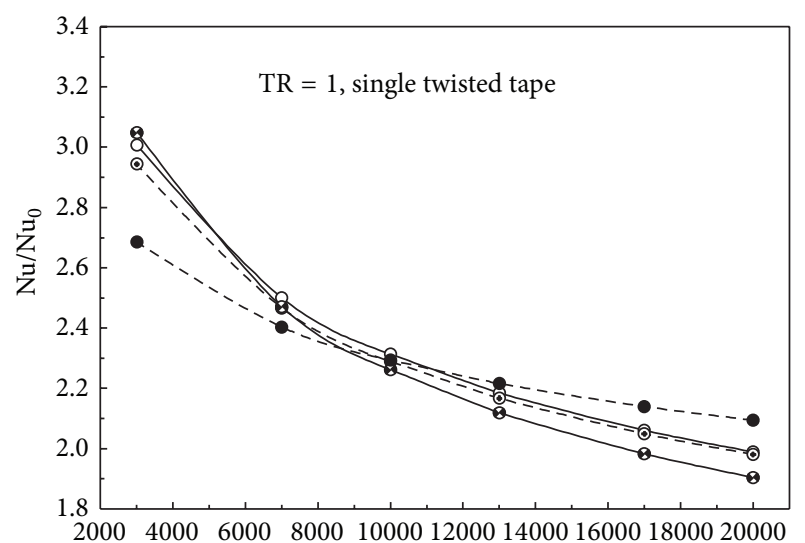

$\operatorname{Re}$

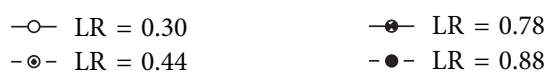

Figure 15: $\mathrm{Nu} / \mathrm{Nu}_{0}$ versus $\mathrm{Re}$ at various LRs.

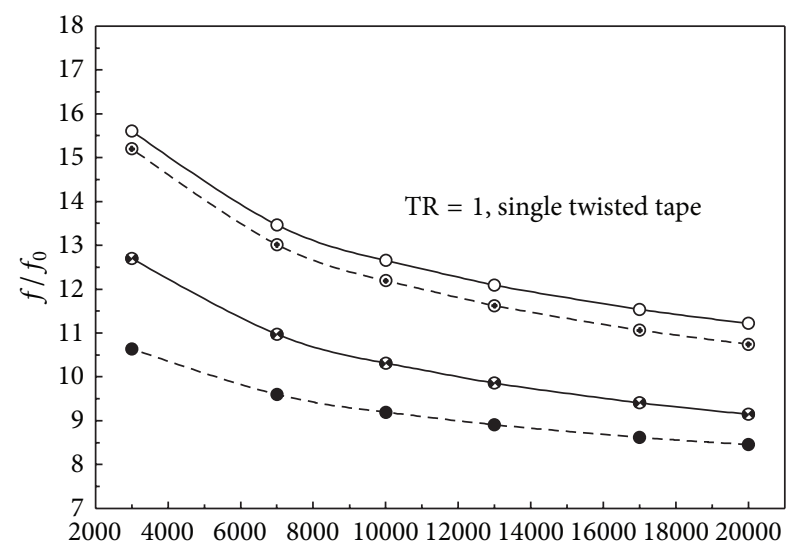

$\mathrm{Re}$

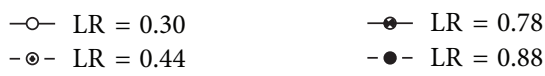

FiguRe 16: $f / f_{0}$ versus Re at various LRs. 


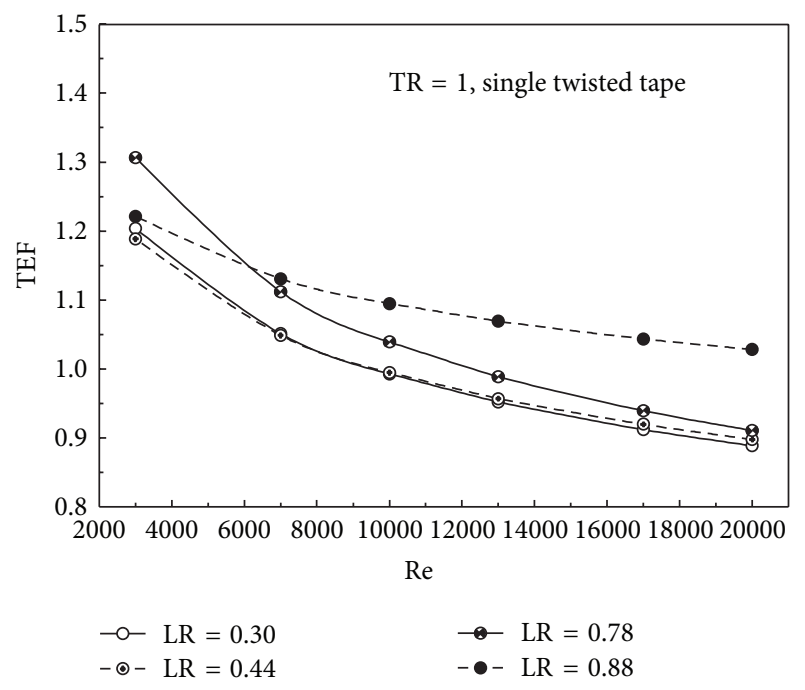

FIgURE 17: TEF versus Re at various LRs.

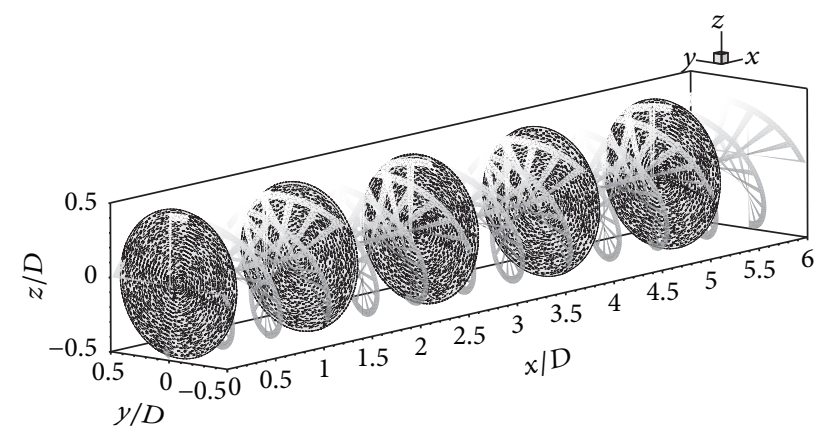

FIGURE 18: Tangential velocity vectors in transverse planes for the double-modified-twisted tape in the tube at $\mathrm{Re}=10,000, \mathrm{LR}=0.78$, and $\mathrm{TR}=1$.

\section{Conclusion}

The modified-twisted tapes are improved to augment the heat transfer rate and thermal performance with reducing of the pressure loss in the circular tube heat exchanger. The twisted tape is punched with rectangular holes at various length ratios and inserted in the middle of the test tube. The effects of the length ratios $(\mathrm{LR}=0.30,0.44,0.78$, and 0.88$)$, twisted ratios $(\mathrm{TR}=1,1.5,2$, and 4$)$, and configurations are investigated for the turbulent regime, $\mathrm{Re}=3000-20,000$. The numerical method is selected to study heat transfer characteristic, flow configuration, and performance assessment in the test tube. The major conclusions are as follows.

(i) The longitudinal vortex flows, which are created by the modified-twisted tape, are found similar to regular twisted tape. The vortex flows help to a better fluid mixing that leads to enhance the heat transfer rate and thermal performance with reducing the pressure loss.

(ii) Similar to $\mathrm{LR}$, the $\mathrm{TR}=1$ performs the highest heat transfer rate and friction loss, while the $\mathrm{TR}=4$ provides the reverse result. The optimum thermal enhancement factor is found at $\mathrm{TR}=1$ around 1.23.

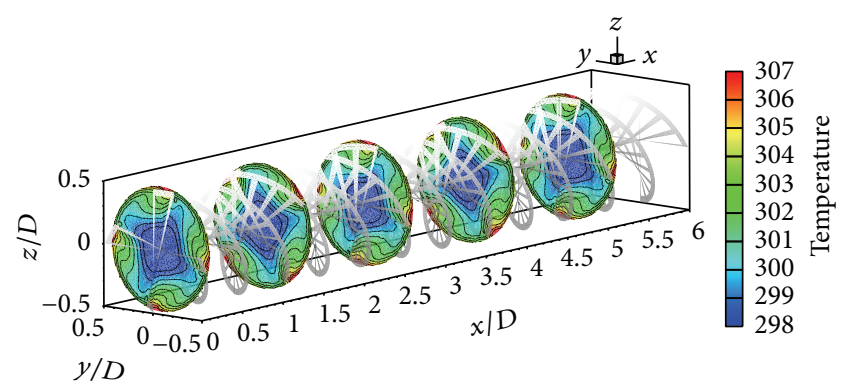

FIGURE 19: Temperature contours in transverse planes for the double-modified-twisted tape in the tube at $\mathrm{Re}=10,000, \mathrm{LR}=0.78$, and $\mathrm{TR}=1$.

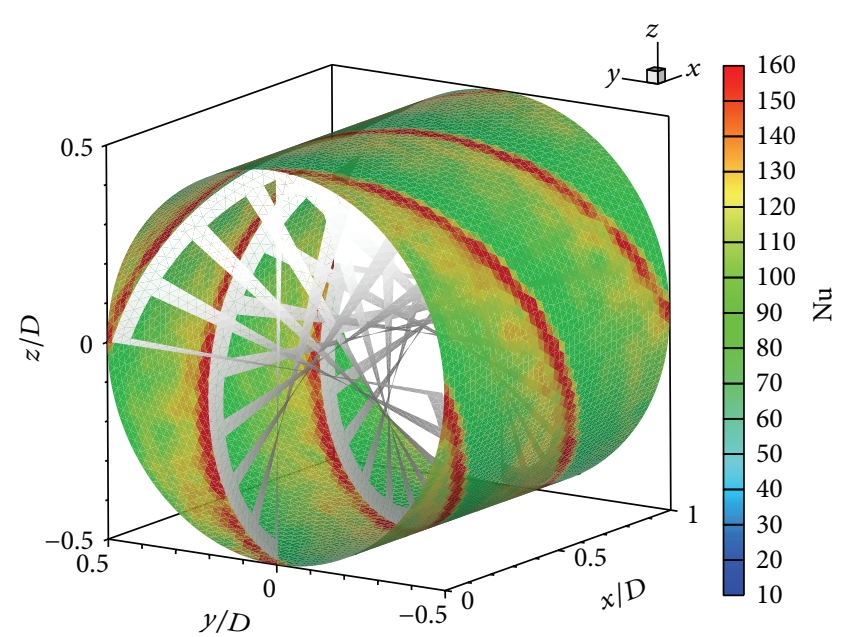

FIGURE 20: Local Nusselt number contours on the tube wall for the double-modified-twisted tape in the tube at $\operatorname{Re}=10,000, \mathrm{LR}=0.78$, and $\mathrm{TR}=1$.

The large twisted ratio helps to reduce the pressure loss in the heating system.

(iii) The LR $=0.88$ gives the lowest friction loss, while the $\mathrm{LR}=0.30$ performs the opposite result. The heat transfer rates of $\mathrm{LR}=0.30,0.44$, and 0.78 are found to be very close. The $L R=0.88$ provides the lowest Nusselt number for $3000 \leq \mathrm{Re} \leq 10,000$, but the $\mathrm{LR}=$ 0.88 gives the highest heat transfer rate when $\mathrm{Re}>$ 10,000 . The $\mathrm{LR}=0.78$ makes the highest $\mathrm{TEF}$ at $\mathrm{Re}=$ 3000. The $L R=0.88$ performs the TEF higher than the smooth tube for all the Reynolds number (TEF > 1 ), while the $\mathrm{LR}=0.30,0.44$, and 0.78 gives the $\mathrm{TEF}$ upper unity when $\operatorname{Re}<10,000$.

(iv) The double modified-twisted tapes give higher heat transfer and thermal enhancement factor than the single modified-twisted tapes due to the peak of heat transfer regime on the tube wall being greater. The longitudinal vortex flows, which are generated by double twisted tapes, are found similar to the single twisted tape. The maximum TEF is found at LR = $0.78, \mathrm{TR}=1, \mathrm{Re}=3000$ of the double modified-twisted tapes. 


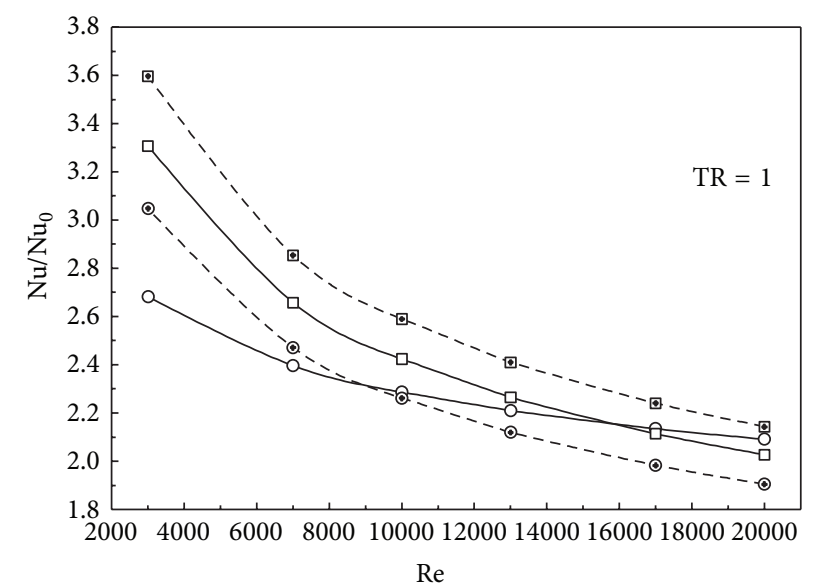

$\multimap-\mathrm{LR}=0.88$, single twisted tape $\square-\mathrm{LR}=0.88$, double twisted tapes -๑ - LR $=0.78$, single twisted tape - - $-\mathrm{LR}=0.78$, double twisted tapes

FIgURE 21: $\mathrm{Nu} / \mathrm{Nu}_{0}$ versus $\mathrm{Re}$ at various cases.

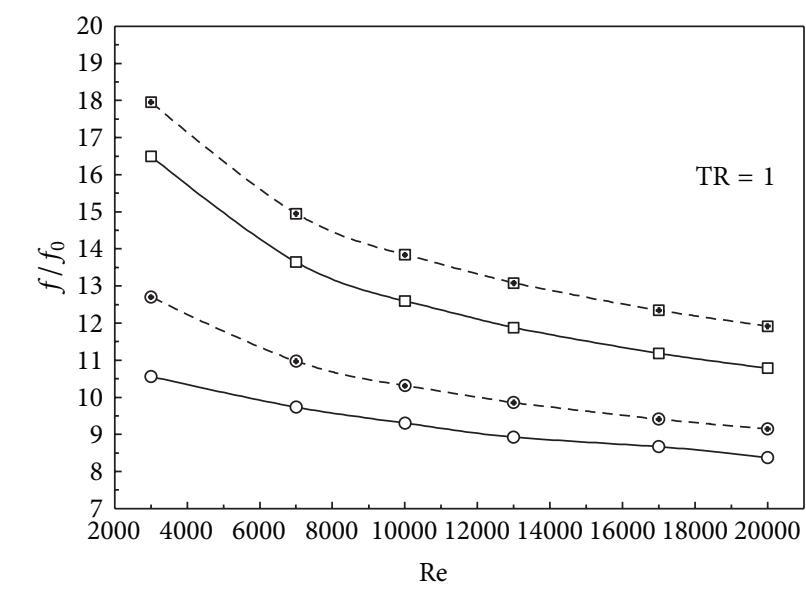

$\multimap-\mathrm{LR}=0.88$, single twisted tape $\rightarrow-\mathrm{LR}=0.88$, double twisted tapes -๑- LR $=0.78$, single twisted tape - - $-\mathrm{LR}=0.78$, double twisted tapes

Figure 22: $f / f_{0}$ versus Re at various cases.

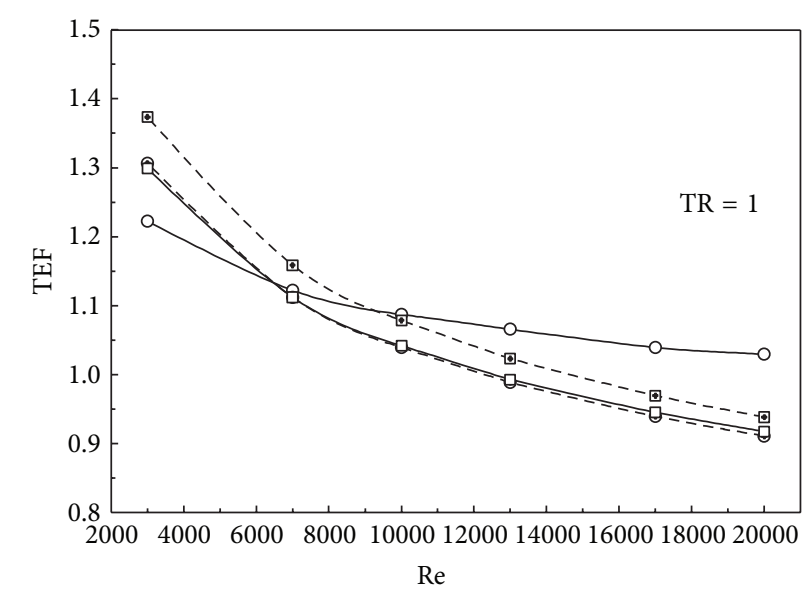

$\multimap-$ LR $=0.88$, single twisted tape $\square-\mathrm{LR}=0.88$, double twisted tapes -๑- LR $=0.78$, single twisted tape - - $-\mathrm{LR}=0.78$, double twisted tapes

FIGURE 23: TEF versus Re at various cases.

\section{Nomenclature}

D: $\quad$ Diameter of the tube, $\mathrm{m}$

$e$ : Rectangular hole width, $m$

g: Gap between rectangular holes, $\mathrm{m}$

$f: \quad$ Friction factor

$h$ : Convective heat transfer coefficient, $\mathrm{W} \mathrm{m}^{-2} \mathrm{~K}^{-1}$

$k: \quad$ Turbulent kinetic energy $\left(k=(1 / 2) \overline{u_{i}^{\prime} u_{j}^{\prime}}\right)$

$k_{a}$ : Thermal conductivity of air, $\mathrm{W} \mathrm{m}^{-1} \mathrm{~K}^{-1}$

l: $\quad$ Rectangular hole length, $\mathrm{m}$

LR: Length ratio $(l / W)$

$\mathrm{Nu}$ : Nusselt number

$P$ : $\quad$ Static pressure, $\mathrm{Pa}$

Pr: Prandtl number

Re: Reynolds number $\left(\rho u_{0} D / \mu\right)$

$T$ : Temperature, $\mathrm{K}$

TEF: Thermal performance enhancement factor $\left(\mathrm{Nu} / \mathrm{Nu}_{0}\right) /\left(f / f_{0}\right)^{1 / 3}$

TR: Twisted ratio $(y / W)$

$u_{i}$ : Velocity component in $x_{i}$-direction, $\mathrm{m} \mathrm{s}^{-1}$

$u_{i}^{\prime}$ : $\quad$ Fluctuation velocity in $x_{i}$-direction, $\mathrm{m} \mathrm{s}^{-1}$

$u_{0}$ : Mean or uniform velocity in smooth tube, $\mathrm{m} \mathrm{s}^{-1}$

$W$ : Twisted tape width, $\mathrm{m}$

$x$ : Coordinate direction

$y: \quad$ Twisted pitch, $\mathrm{m}$.

\section{Greek Letters}

$\mu$ : Dynamic viscosity, $\mathrm{kg} \mathrm{s}^{-1} \mathrm{~m}^{-1}$

$\Gamma$ : Thermal diffusivity

$\varepsilon$ : Dissipation rate

$\rho$ : Density, $\mathrm{kg} \mathrm{m}^{-3}$.

\section{Subscript}

0: Smooth tube

pp: Pumping power.

\section{Conflict of Interests}

The authors declare that there is no conflict of interests regarding the publication of this paper.

\section{Acknowledgments}

This research was funded by College of Industrial Technology, King Mongkut's University of Technology North Bangkok, Thailand, and King Mongkut's Institute of Technology Ladkrabang research fund. The authors would like to thank Associate Professor Dr. Pongjet Promvonge for suggestions.

\section{References}

[1] N. Piriyarungrod, S. Eiamsa-Ard, C. Thianpong, M. Pimsarn, and K. Nanan, "Heat transfer enhancement by tapered twisted tape inserts," Chemical Engineering and Processing: Process Intensification, vol. 96, pp. 62-71, 2015.

[2] P. Promvonge, "Thermal performance in square-duct heat exchanger with quadruple V-finned twisted tapes," Applied Thermal Engineering, vol. 91, pp. 298-307, 2015. 
[3] V. Hindasageri, R. P. Vedula, and S. V. Prabhu, "Heat transfer distribution of swirling flame jet impinging on a flat plate using twisted tapes," International Journal of Heat and Mass Transfer, vol. 91, pp. 1128-1139, 2015.

[4] S. Eiamsa-ard, K. Kiatkittipong, and W. Jedsadaratanachai, "Heat transfer enhancement of $\mathrm{TiO}_{2}$ /water nanofluid in a heat exchanger tube equipped with overlapped dual twisted-tapes," Engineering Science and Technology, vol. 18, no. 3, pp. 336-350, 2015.

[5] E. Y. Rios-Iribe, M. E. Cervantes-Gaxiola, E. Rubio-Castro et al., "Heat transfer analysis of a non-Newtonian fluid flowing through a circular tube with twisted tape inserts," Applied Thermal Engineering, vol. 84, pp. 225-236, 2015.

[6] S. Chokphoemphun, M. Pimsarn, C. Thianpong, and P. Promvonge, "Thermal performance of tubular heat exchanger with multiple twisted-tape inserts," Chinese Journal of Chemical Engineering, vol. 23, no. 5, pp. 755-762, 2015.

[7] M. Khoshvaght-Aliabadi and M. Eskandari, "Influence of twist length variations on thermal-hydraulic specifications of twisted-tape inserts in presence of $\mathrm{Cu}$-water nanofluid," Experimental Thermal and Fluid Science, vol. 61, pp. 230-240, 2015.

[8] S. D. Salman, A. A. H. Kadhum, M. S. Takriff, and A. B. Mohamad, "CFD analysis of heat transfer and friction factor characteristics in a circular tube fitted with quadrant-cut twisted tape inserts," Mathematical Problems in Engineering, vol. 2013, Article ID 273764, 8 pages, 2013.

[9] H. Maddah, M. Alizadeh, N. Ghasemi, and S. R. W. Alwi, "Experimental study of $\mathrm{Al}_{2} \mathrm{O}_{3}$ /water nanofluid turbulent heat transfer enhancement in the horizontal double pipes fitted with modified twisted tapes," International Journal of Heat and Mass Transfer, vol. 78, pp. 1042-1054, 2014.

[10] S. D. Salman, A. A. H. Kadhum, M. S. Takriff, and A. B. Mohamad, "CFD simulation of heat transfer and friction factor augmentation in a circular tube fitted with elliptic-cut twisted tape inserts," Mathematical Problems in Engineering, vol. 2013, Article ID 163839, 7 pages, 2013.

[11] F. T. Kanizawa, T. S. Mogaji, and G. Ribatski, "Evaluation of the heat transfer enhancement and pressure drop penalty during flow boiling inside tubes containing twisted tape insert," Applied Thermal Engineering, vol. 70, no. 1, pp. 328-340, 2014.

[12] S. Pal and S. K. Saha, "Laminar flow and heat transfer through a circular tube having integral transverse corrugations and fitted with centre-cleared twisted-tape," Experimental Thermal and Fluid Science, vol. 57, pp. 388-395, 2014.

[13] M. T. Naik, S. S. Fahad, L. Syam Sundar, and M. K. Singh, "Comparative study on thermal performance of twisted tape and wire coil inserts in turbulent flow using $\mathrm{CuO}$ /water nanofluid," Experimental Thermal and Fluid Science, vol. 57, pp. 65-76, 2014.

[14] P. Eiamsa-ard, N. Piriyarungroj, C. Thianpong, and S. Eiamsaard, "A case study on thermal performance assessment of a heat exchanger tube equipped with regularly-spaced twisted tapes as swirl generators," Case Studies in Thermal Engineering, vol. 3, pp. 86-102, 2014.

[15] W. H. Azmi, K. V. Sharma, P. K. Sarma, R. Mamat, and S. Anuar, "Comparison of convective heat transfer coefficient and friction factor of $\mathrm{TiO}_{2}$ nanofluid flow in a tube with twisted tape inserts," International Journal of Thermal Sciences, vol. 81, no. 1, pp. 8493, 2014.

[16] S. D. Salman, A. A. H. Kadhum, M. S. Takriff, and A. B. Mohamad, "Heat transfer enhancement of laminar nanofluids flow in a circular tube fitted with parabolic-cut twisted tape inserts," The Scientific World Journal, vol. 2014, Article ID 543231, 7 pages, 2014.

[17] S. D. Salman, A. A. H. Kadhum, M. S. Takriff, and A. B. Mohamad, "Numerical investigation of heat transfer and friction factor characteristics in a circular tube fitted with V-cut twisted tape inserts," The Scientific World Journal, vol. 2013, Article ID 492762, 8 pages, 2013.

[18] S. Ghadirijafarbeigloo, A. H. Zamzamian, and M. Yaghoubi, "3-D numerical simulation of heat transfer and turbulent flow in a receiver tube of solar parabolic trough concentrator with louvered twisted-tape inserts," Energy Procedia, vol. 49, pp. 373380, 2014.

[19] W. H. Azmi, K. V. Sharma, R. Mamat, and S. Anuar, "Turbulent forced convection heat transfer of nanofluids with twisted tape insert in a plain tube," Energy Procedia, vol. 52, pp. 296-307, 2014.

[20] D. R. Waghole, R. M. Warkhedkar, V. S. kulkarni, and R. K. Shrivastva, "Experimental investigations on heat transfer and friction factor of silver nanofliud in absorber/receiver of parabolic trough collector with twisted tape inserts," Energy Procedia, vol. 45, pp. 558-567, 2014.

[21] P. V. Durga Prasad, A. V. S. S. K. S. Gupta, M. Sreeramulu, L. S. Sundar, M. K. Singh, and A. C. M. Sousa, "Experimental study of heat transfer and friction factor of $\mathrm{Al}_{2} \mathrm{O}_{3}$ nanofluid in $\mathrm{U}$-tube heat exchanger with helical tape inserts," Experimental Thermal and Fluid Science, vol. 62, pp. 141-150, 2015.

[22] H. Maddah, R. Aghayari, M. Farokhi, S. Jahanizadeh, and K. Ashtary, "Effect of twisted-tape turbulators and nanofluid on heat transfer in a double pipe heat exchanger," Journal of Engineering, vol. 2014, Article ID 920970, 9 pages, 2014.

[23] M. M. K. Bhuiya, M. S. U. Chowdhury, M. Saha, and M. T. Islam, "Heat transfer and friction factor characteristics in turbulent flow through a tube fitted with perforated twisted tape inserts," International Communications in Heat and Mass Transfer, vol. 46, pp. 49-57, 2013.

[24] K. Nanan, K. Yongsiri, K. Wongcharee, C. Thianpong, and S. Eiamsa-ard, "Heat transfer enhancement by helically twisted tapes inducing co- and counter-swirl flows," International Communications in Heat and Mass Transfer, vol. 46, pp. 67-73, 2013.

[25] S. Eiamsa-ard and K. Wongcharee, "Heat transfer characteristics in micro-fin tube equipped with double twisted tapes: effect of twisted tape and micro-fin tube arrangements," Journal of Hydrodynamics Series B, vol. 25, no. 2, pp. 205-214, 2013.

[26] S. Eiamsa-ard, V. Kongkaitpaiboon, and K. Nanan, "Thermohydraulics of turbulent flow through heat exchanger tubes fitted with circular-rings and twisted tapes," Chinese Journal of Chemical Engineering, vol. 21, no. 6, pp. 585-593, 2013.

[27] B. Salam, S. Biswas, S. Saha, and M. M. K. Bhuiya, "Heat transfer enhancement in a tube using rectangular-cut twisted tape insert," Procedia Engineering, vol. 56, pp. 96-103, 2013.

[28] M. T. Naik, G. R. Janardana, and L. S. Sundar, "Experimental investigation of heat transfer and friction factor with waterpropylene glycol based $\mathrm{CuO}$ nanofluid in a tube with twisted tape inserts," International Communications in Heat and Mass Transfer, vol. 46, pp. 13-21, 2013.

[29] B. E. Launder and D. B. Spalding, "The numerical computation of turbulent flows," Computer Methods in Applied Mechanics and Engineering, vol. 3, no. 2, pp. 269-289, 1974. 
[30] S. V. Patankar, Numerical Heat Transfer and Fluid Flow, McGraw-Hill, New York, NY, USA, 1980.

[31] F. Incropera and P. D. Dewitt, Introduction to Heat Transfer, John Wiley \& Sons, 3rd edition, 2006.

[32] H. Bas and V. Ozceyhan, "Heat transfer enhancement in a tube with twisted tape inserts placed separately from the tube wall," Experimental Thermal and Fluid Science, vol. 41, pp. 51-58, 2012. 

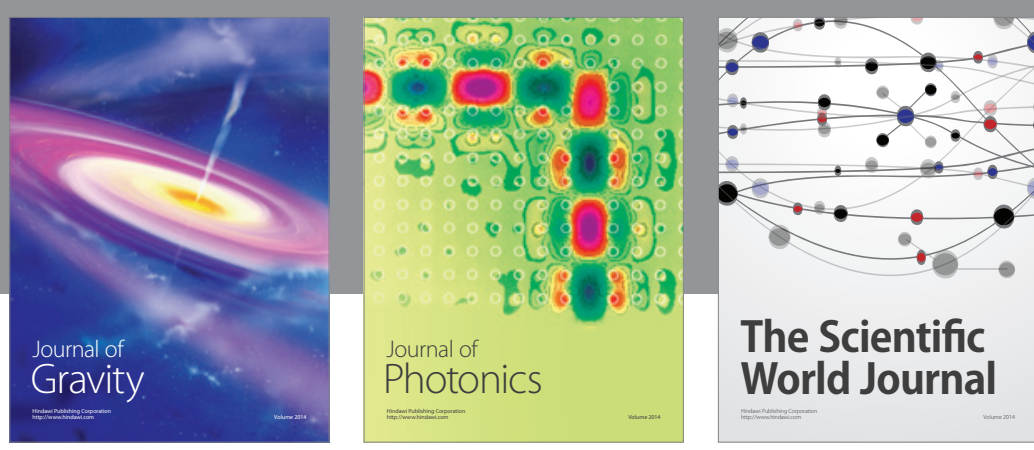

The Scientific World Journal
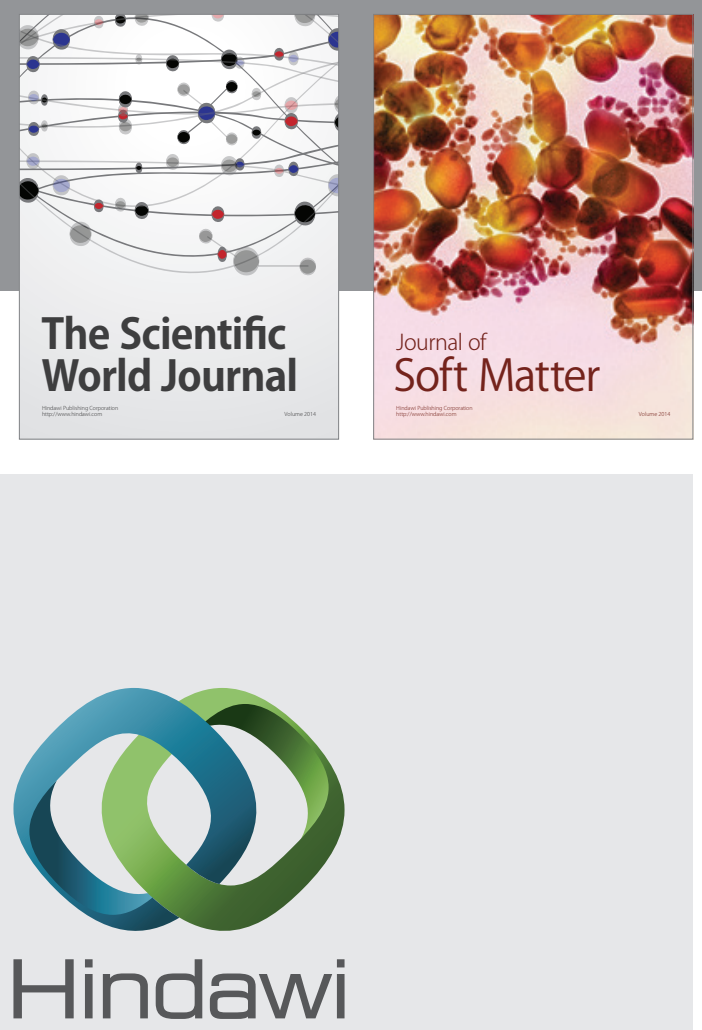

Submit your manuscripts at

http://www.hindawi.com

nternational Journal of

Statistical Mechanics
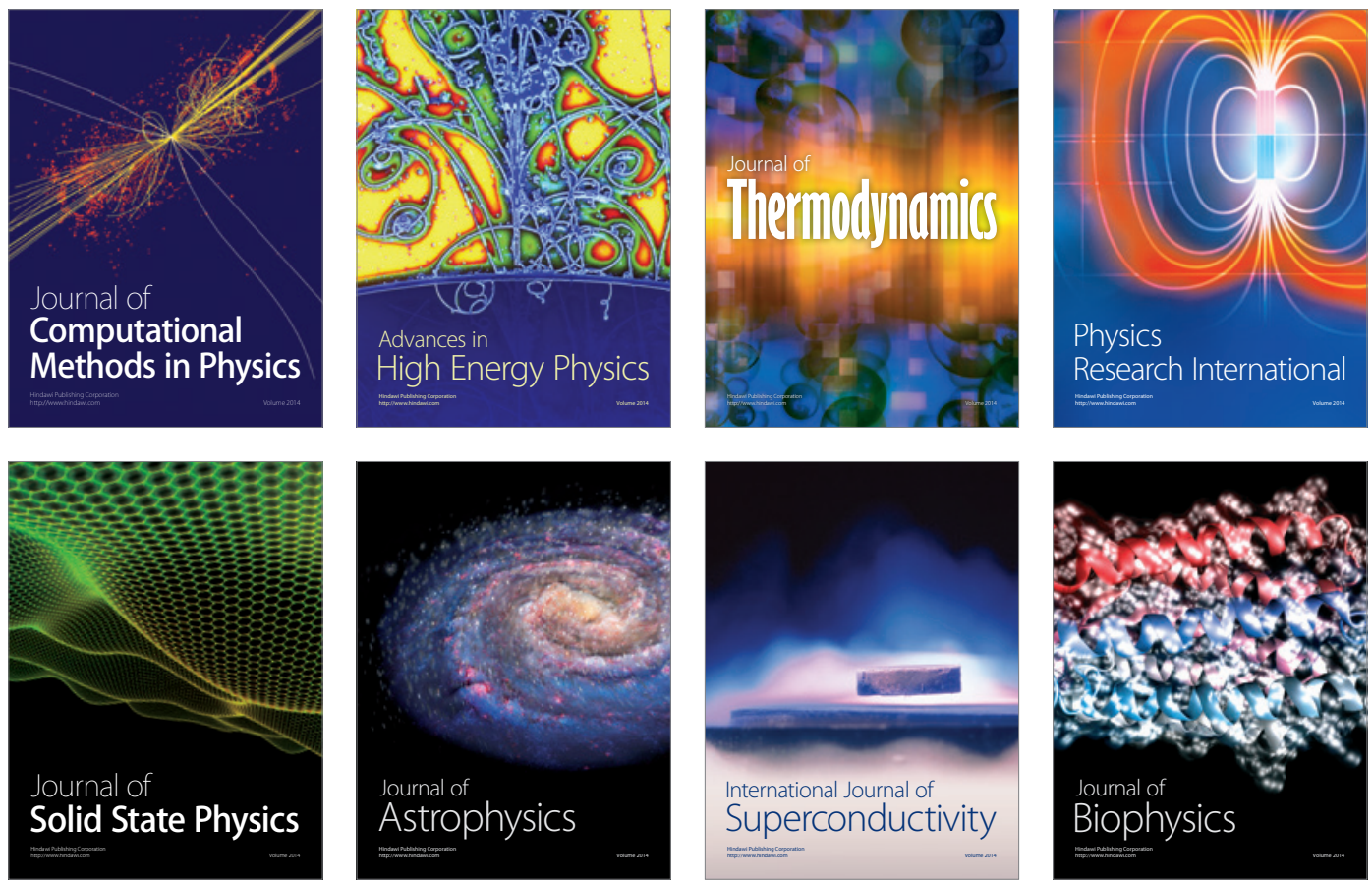
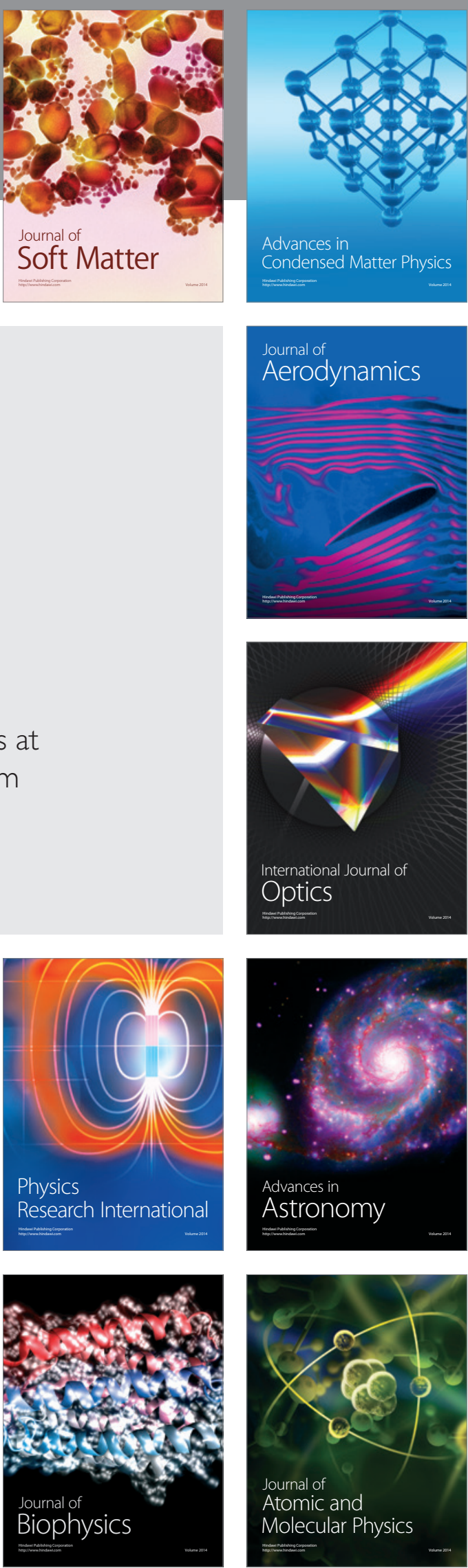